\title{
Self-Healing Supramolecular Hydrogels Based on Reversible Physical Interactions
}

\author{
Satu Strandman and X.X. Zhu * \\ Département de Chimie, Université de Montréal, C.P. 6128, Succursale Centre-ville, Montreal, QC H3C 3J7, \\ Canada; satu.strandman@umontreal.ca \\ * Correspondence: julian.zhu@umontreal.ca; Tel.: +1-514-340-5172
}

Academic Editor: Clemens K. Weiss

Received: 25 February 2016; Accepted: 28 March 2016; Published: 8 April 2016

\begin{abstract}
Dynamic and reversible polymer networks capable of self-healing, i.e., restoring their mechanical properties after deformation and failure, are gaining increasing research interest, as there is a continuous need towards extending the lifetime and improving the safety and performance of materials particularly in biomedical applications. Hydrogels are versatile materials that may allow self-healing through a variety of covalent and non-covalent bonding strategies. The structural recovery of physical gels has long been a topic of interest in soft materials physics and various supramolecular interactions can induce this kind of recovery. This review highlights the non-covalent strategies of building self-repairing hydrogels and the characterization of their mechanical properties. Potential applications and future prospects of these materials are also discussed.
\end{abstract}

Keywords: hydrogels; self-healing; supramolecular materials; non-covalent interactions; dynamic cross-links; physical gels; transient networks; mechanical failure and recovery; self-assembly; host-guest chemistry

\section{Introduction}

Hydrogels are soft solids or solid-like materials that immobilize a large amount of water in a three-dimensional (3D) network held together by covalent bonds, non-covalent or topological interactions [1-4]. These materials are appealing to various applications especially in biology and medicine owing to their compositional and structural versatility that allows introducing responsiveness to external stimuli and adapting them to biological interfaces, high water content and physical properties that are similar to soft tissues or at nanoscale, similar to extracellular matrix [5-13]. Some of the applications of hydrogels in (bio)medical fields include sensors [14-17], actuators [18,19], device coatings [20-22], wound dressings and adhesives [23-25], liquid-absorbing hygiene products [26], delivery vehicles for active compounds or cells [27-30], soft contact lenses [31-33], and matrices and implants in tissue engineering and regenerative medicine [34-37].

There is a continuous need towards extending the lifetime, improving the safety, and enhancing the performance of both soft and hard materials. Mechanical deformation may lead to micro- or macroscale cracks, leading to gradual deterioration or sudden loss of mechanical properties [38,39]. One strategy to improve the performance and extend the lifetime of gels is to introduce self-healing ability, that is, a capacity to restore the initial properties after material failure, using dynamic and reversible linkages [39-45]. A visual demonstration of the self-healing of a hydrogel is shown in Figure 1. The dynamic linkages can be based on reversible covalent chemical bonds, formed for example by Diels-Alder reaction [46-50], disulfide [51-53], imine [54,55], oxime [56], or acylhydrazone [50,52] formation, photocrosslinking [57], radical reactions [58,59], or phenylboronate complexation [60-62], and these have been highlighted in several reviews. Dynamic linkages can also be based on supramolecular non-covalent (physical) interactions, such as crystallization, hydrogen 
bonds, host-guest, hydrophobic or polymer-nanocomposite interactions, or multiple combined interactions. Some of these non-covalent networks can be built from pre-formed colloidal systems, such as liposomes or mixed micelles.

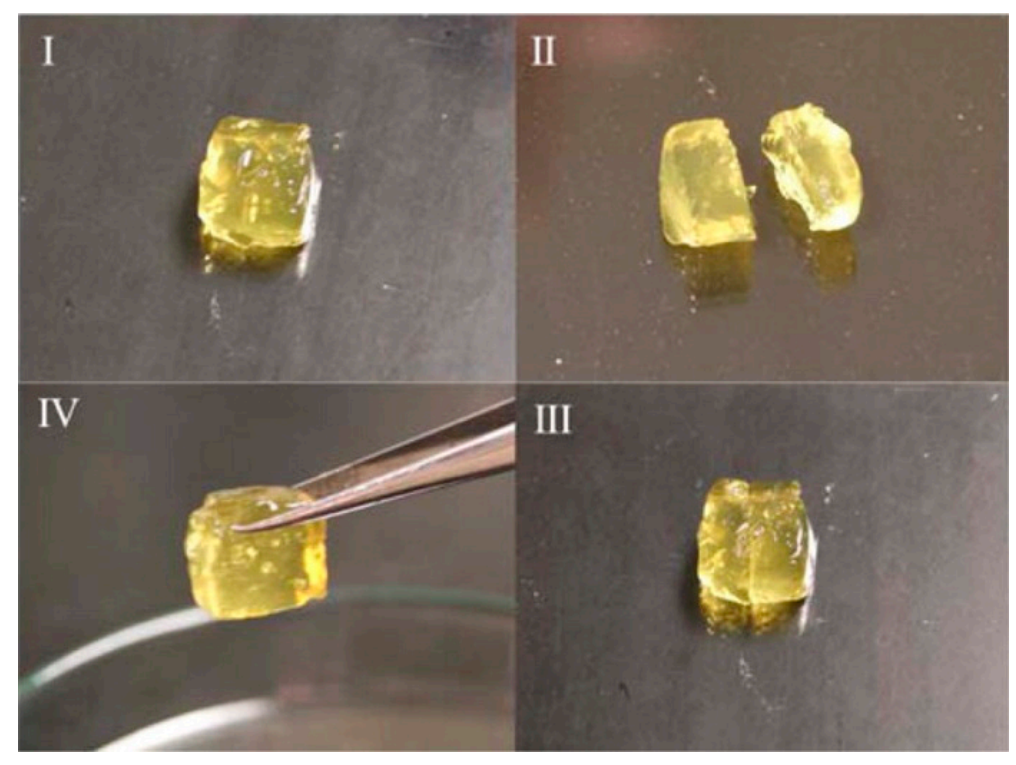

Figure 1. Visual evidence of self-healing of a supramolecular hydrogel through non-covalent host-guest interactions between $\beta$-cyclodextrin- and bile acid-bearing polymers: (I) initial hydrogel sample; (II) sliced sample; (III) sliced sample rejoined for healing; and (IV) self-healed sample. Reprinted from [63] with permission. Copyright 2016 American Chemical Society.

Physical transient gels are considered as a model system in soft materials physics with their well-defined structural properties, ease of preparation, and relatively simple linear rheological behavior, although their non-linear rheological response can be highly complex [38]. Recent reviews have focused on hard and/or chemically crosslinked self-healing materials [41,43,45,48,64] or on certain classes of supramolecular polymers, such as hydrogen-bonded or metal-ligand-coordinated systems [40,42,44,65-67]. Wang and Heilshorn [68] highlighted the potential of adaptable hydrogels in cell encapsulation. As non-covalently crosslinked gels often show rapid structure recovery, they are gaining increasing interest in injectable and extrudable systems used in therapeutic delivery or additive manufacturing (3D printing). These applications require the knowledge of the precise recovery rate and mechanical properties of the gels. For example, the tailored elasticity of the extracellular matrix-mimicking hydrogels as bio-inks is crucial for the cell differentiation and survival, while injectable gels should have sufficient strength after structure recovery to hold them in place. These reviews have emphasized the chemistry for the making of the physical gels rather than their resulting physical properties. The self-healing phenomenon is mostly based on visual demonstrations. Further understanding of the relation of the design, structure, and properties is in the call for new developments in this area. We attempt to fill this gap by presenting the preparation strategies in relation to the mechanical properties of the self-healing gels through examples along with a review of the methods used for mechanical testing of self-healing characteristics. We will then discuss the potential applications where gel strength and fast recovery play an important role and present the future prospects of reversible physical gels.

\section{Characterization of the Self-Healing Behavior}

The term "self-healing" has been used to describe various structure recovery processes of hydrogels, where the gels revert to their original state and recover the mechanical strength completely or partially after the deformation or fracture. The gelation and structure recovery can take place via 
different interactions and self-assembling processes. The viscoelastic properties of physical networks are determined by the number and lifetime of crosslinks, and these further affect the kinetics of the self-repair $[69,70]$. In addition to macroscopic healing, transient chain association causes temporal evolution of microscopic topology, leading to changes in mechanical properties [71]. Therefore, both macroscopic rheology and microscopic fluorescence results have been used as a basis for theoretical models that aim at quantitative prediction of chain association dynamics in physical networks [69-71]. Common experimental methods to characterize the self-healing behavior of hydrogels include:

- Visual observation. Freshly cut or damaged pieces of a hydrogel are brought in contact and their rejoining to form a uniform gel is followed both visually and using a simple qualitative mechanical deformation, that is, stretching or bending the sample. Examples are shown in Figure 1 and in several figures below. Visual observation can be accompanied by microscopic imaging techniques (confocal, scanning electron microscopy SEM) to reveal the micro- or nanoscale structure recovery.

- Oscillatory rheology: Step strain measurement. After determining the yield stress/strain and the recovery time of the gel sample, the gel will be exposed to strain that alternates periodically between low (structure conservation or recovery) and high values (structure breaking) at constant oscillation frequency. This test allows for the quantitative determination of equilibrium moduli and the extent of structure recovery (recovery rate). Several examples of step strain tests will be shown in Section 3.

- Cyclic compression/tensile testing. Self-healing of hydrogels can be tested by cyclic compression or tensile tests, each cycle followed by a recovery period. The changes in stress/strain curves and fracture point or in initial compressive modulus give information on the recovery of ruptured crosslinks. Tensile tests can be used to quantify the self-healing efficiency after joining the fractured surfaces of a ruptured hydrogel by comparing the elongation at break for an intact and re-joint hydrogel. Figure 2 shows an example of a compression test of a physically crosslinked hydrogel and a hybrid gel with combined chemical and physical crosslinking, as well as the compression and elongation curves for a physically crosslinked gel (no chemical crosslinker). Here, the nominal stress $\sigma_{\text {nom }}$ is the force per cross-sectional area of the un-deformed gel specimen and the strain is represented by $\lambda$, the deformation ratio (deformed length/initial length). The hysteresis in the compression and elongation curves indicates the decreased number of crosslinks and thus, reduced structure recovery over the deformation cycles [72].

One of the challenges of physically crosslinked gels is optimizing the strength and self-healing properties, as the rigidity of gels limits the chain diffusion to the damaged site. Despite the versatility of supramolecular hydrogels, they suffer from relatively low storage moduli ( $\mathrm{G}^{\prime}$ in $\mathrm{Pa}-\mathrm{kPa}$ range) and so far, combining them with reversible or irreversible covalent networks or harder domains has provided the best mechanical strength. For example, a single component PVA hydrogel with H-bonded crystalline domains could reach a fracture stress of $\sim 280 \mathrm{kPa}$ initially and $\sim 200 \mathrm{kPa}$ after $48 \mathrm{~h}$ healing (72\% of original strength) [73], and nanocomposite gels of hydrophobically modified polyacrylamide and graphene oxide (GO) could achieve tensile stress of $243 \mathrm{kPa}$, but the recovery rate was low, 44\%. For comparison, the same gel without the reinforcing GO showed a tensile strength of $52 \mathrm{kPa}$ [74]. 

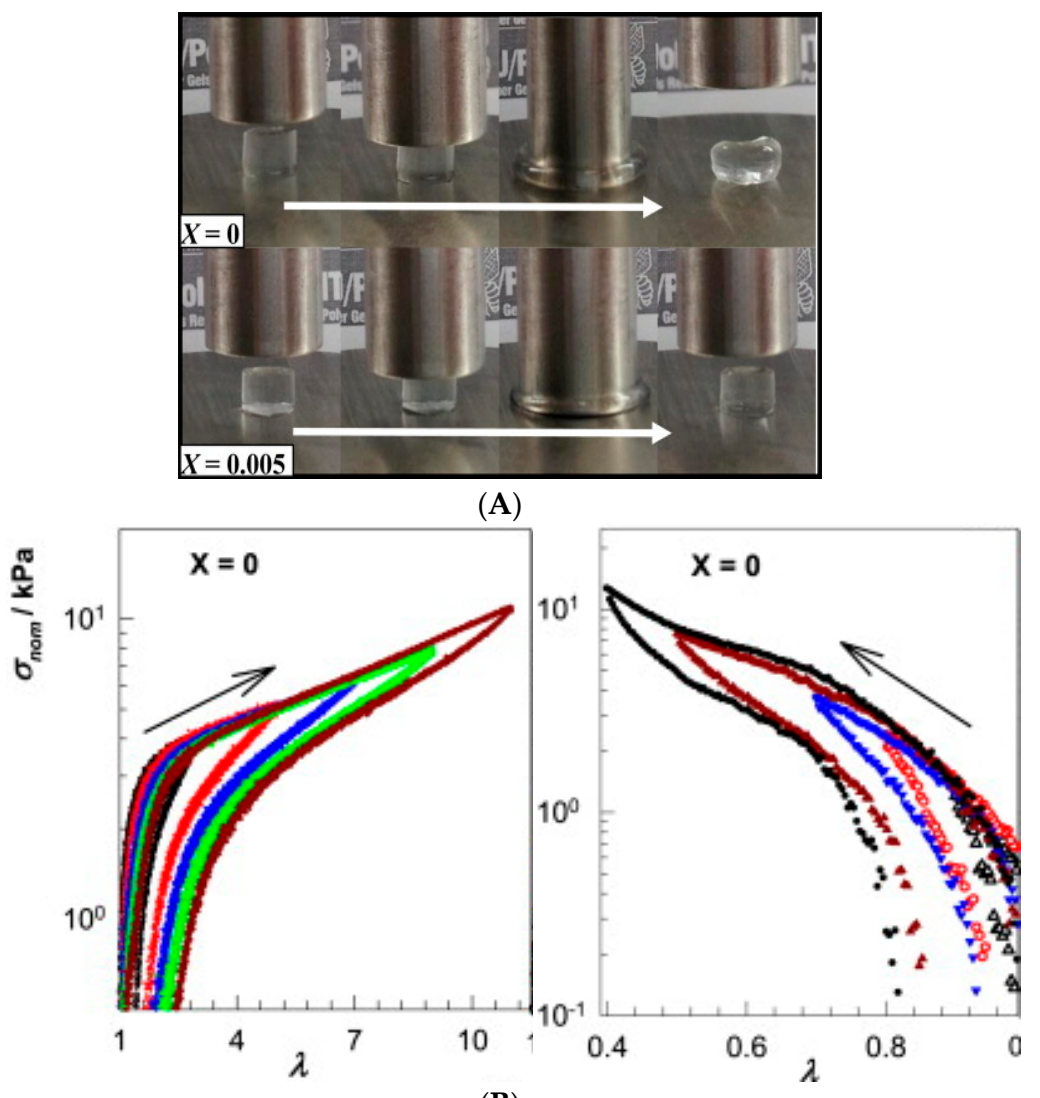

(B)

Figure 2. (A) Photographs of the physical (molar ratio of chemical crosslinker vs. monomer $X=0$ ) and hybrid gels with combined chemical and physical crosslinking $(X=0.005)$ during the compression tests. The physical gel remains deformed after removal of the stress (top-right image); (B) Nominal stress $\sigma_{\text {nom }} v s$. deformation ratio $\lambda$ curves from cyclic elongation (left) and compression tests (right) for a physically crosslinked gel $(X=0)$. Reprinted from [72] with permission, Copyright 2016 Elsevier.

\section{Preparation Strategies}

\subsection{Hydrophobic Interactions}

Hydrophobicity gives rise to unusual properties of aqueous solutions of nonpolar compounds and plays a key role in a variety of chemical and biophysical phenomena, such as protein folding or self-assembly of amphiphiles into micelles and membranes [75]. Hydrophobic interactions are different from other noncovalent interactions as they do not depend on direct intermolecular attraction between interacting species but are rather driven by the tendency of water molecules to retain their H-bonded network intact around a nonpolar solute, altered by increased temperature, the presence of cosolutes, and size and curvature of nonpolar species [76]. Resulting molecular rearrangement can lead to complex colloidal behavior of amphiphilic molecules in aqueous solutions. Polymer-based hydrogels formed through hydrophobic interactions can be made by introducing hydrophobic sequences within or in the ends of hydrophilic polymer chains [77]. The transient network formation through interchain interactions depends on polymer concentration, fraction of hydrophobic moieties, and polymer architecture [77-79]. Such non-covalent hydrogels may exhibit self-healing capacity owing to the dynamic and reversible nature of the junctions [80].

Self-healing associating networks of hydrophobically modified water-soluble polymers have been made by micellar copolymerization of (1) hydrophilic comonomers, such as acrylic acid (AAc), acrylamide (AAm) or $N$-alkylacrylamides ( $N, N$-dimethylacrylamide, $N$-isopropylacrylamide); with (2) large hydrophobic monomers, such as stearyl methacrylate (C18) [80-84], dococyl acrylate (C22) [81]; 
octylphenyl polyethoxyether acrylate [85] in the presence of (3) a surfactant (sodium dodecyl sulfate SDS, cetyltrimethyl ammonium bromide CTAB) and depending on the hydrophobe; (4) salt ( $\mathrm{NaCl}$, $\mathrm{NaBr}$ ) or a cosurfactant. Micellar radical copolymerization in aqueous solution is a common technique for the synthesis of associative copolymers. However, unlike smaller hydrophobic $N$-alkylacrylamides or $\mathrm{N}$-alkyl(meth)acrylates (C4-C12), long-chain alkyl(meth)acrylates have very low water-solubility. The addition of sufficient amount of salt or cosurfactant induces the growth and/or morphological transition of surfactant micelles. Larger micelles can then solubilize a high amount of hydrophobes, whereupon they can grow further (catanionic CTAB-SDS system) or adopt a different morphology (SDS-NaCl system) for thermodynamic feasibility [81,82]. C18- and C22-acrylamide copolymer gels with a SDS- $\mathrm{NaCl}$ system reached final elastic modulus $\mathrm{G}^{\prime}$ of around $1 \mathrm{kPa}$ at $1 \mathrm{~Hz}$ and $\tan \delta$ of $0.5-0.9$, monitored with a rotational rheometer during the polymerization.

Okay group found that after the copolymerization, the hydrogels became mechanically stronger upon swelling and extraction of surfactant micelles, as the hydrophobic interactions became enhanced without surfactant [81]. The tensile strength of a C18-acrylamide copolymer gel increased from $12 \pm 1 \mathrm{kPa}$ to $78 \pm 6 \mathrm{kPa}$ after the removal of SDS micelles by equilibrium swelling in water, but at the same time the elongation at break decreased from $2200 \% \pm 350 \%$ to $650 \% \pm 80 \%$, indicating increased stiffness of the gel. At the same time, the gels lost their ability to self-heal because of longer lifetimes of hydrophobic associations. The self-healing property was tested by a tensile strength test on a series of hydrogel samples before and after joining the fractured surfaces of ruptured gels. The results indicate that the self-healing capacity of hydrophobically modified PAAm gels requires the presence of hydrophobe-solubilizing surfactant micelles [81] and possibly a charged comonomer for electrostatic trapping of oppositely charged micelles, such as AAc for trapping mixed micelles of C18 and CTAB (Figure 3) [80,84]. The self-healing efficiency increases with decreasing lifetime of dynamic crosslinks due to favorable chain diffusion across the fractured surfaces. Therefore, improving the gel strength by enchancing the hydrophobic interactions or even combining physical and covalent crosslinking (hybrid gels) [72], takes a toll on the self-healing capacity and balancing these two characteristics is important in optimizing the gel performance.
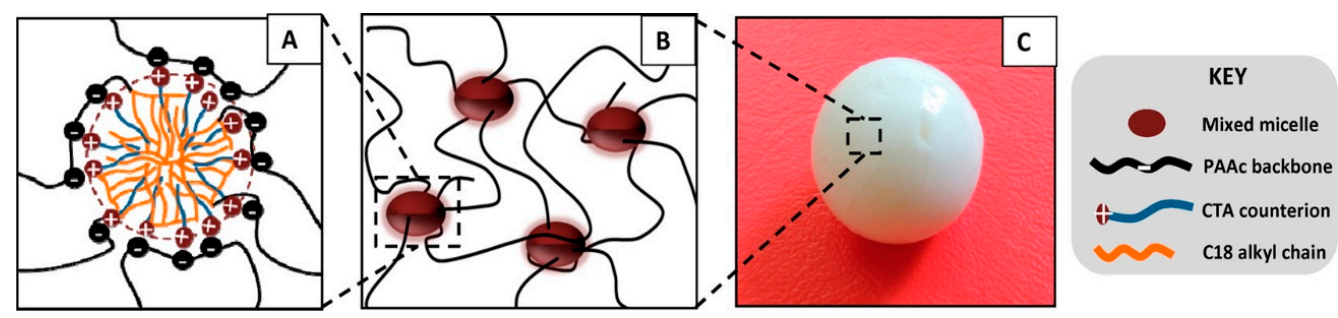

Figure 3. (A,B) Cartoon showing the cross-link in self-healing hydrophobically modified poly(acrylic acid) (PAAc) hydrogels; (C) Image of a PAAc hydrogel sample in the form of a sphere in equilibrium with water. The mixed micelles consist of stearyl methacrylate (C18) and CTAB in aqueous $\mathrm{NaBr}$ solution. Reprinted with permission from [80]. Copyright 2016 American Chemical Society.

Another method for preparing a hydrophobically associated self-healing hydrogel is introducing reversible network junctions through liposomes that can anchor the hydrophobic moieties of (co)polymers into their bilayer. As liposomes have found clinical applications as drug carriers [86], their delivery to a specific site in the body could be achieved via injectable, rapidly self-healing hydrogels. Mixing a telechelic cholesterol (Chol) end group-bearing poly(ethylene glycol) (PEG) with dimethyldioctadecylammonium bromide (DODAB) liposomes resulted in an elastic self-healing gel where Chol-PEG-Chol acted as a dynamic crosslinker between the liposomes (Figure 4) [87]. High liposome concentration and low temperature favored the network formation through higher probability of bridging and lower mobility of Chol groups into and out of liposome bilayers, respectively. The plateau modulus $\mathrm{G}_{0}$ at high oscillatory frequencies in rheological experiments 
showed a crosslinker concentration (C) dependence of $\mathrm{G}_{0} \sim \mathrm{C}^{4.3}$ (vs. $\sim \mathrm{C}^{2.25}$ of Cates model for living polymers and flexible wormlike micelles), which suggests that the interactions between the liposome and crosslinker are more complex than those in a simple polymer network. The highest Chol-PEG-Chol concentration $(6 \% w / v)$ gave $G_{0}$ of $5.5 \mathrm{kPa}$. The gels showed instantaneous self-healing after subjecting them to low stress (yield stress $59 \mathrm{~Pa}$ at $C=3 \% w / v$ ), which is assigned to the re-insertion of Chol groups into liposomes after stress-induced breaking of Chol-PEG-Chol bridges. This gives promise to applications in injectable drug delivery systems and 3D tissue engineering scaffolds [87]. However, the observed body temperature-induced softening of the gel may limit its medical applications and further tuning of the gel strength may be required.

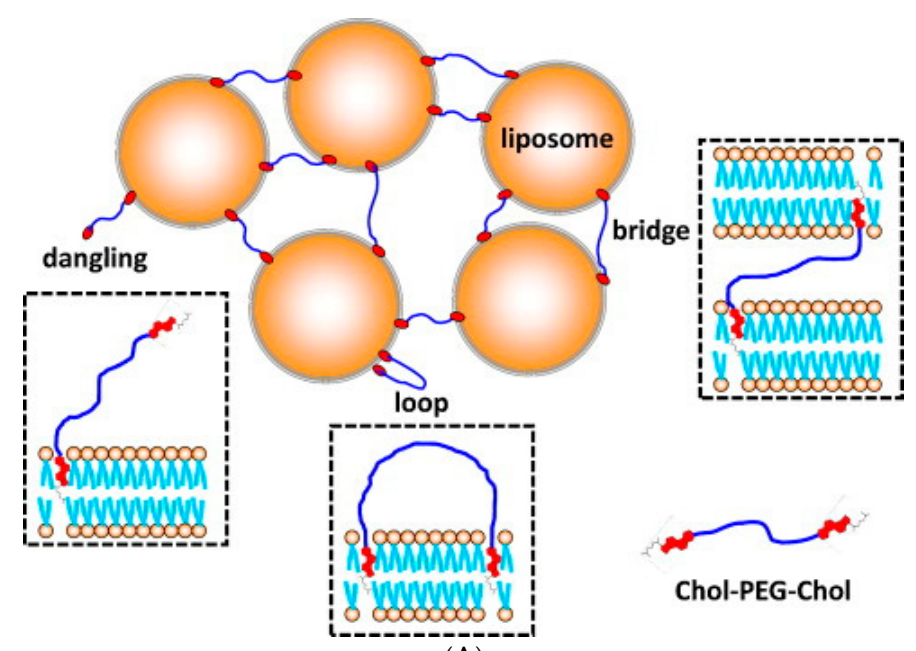

(A)

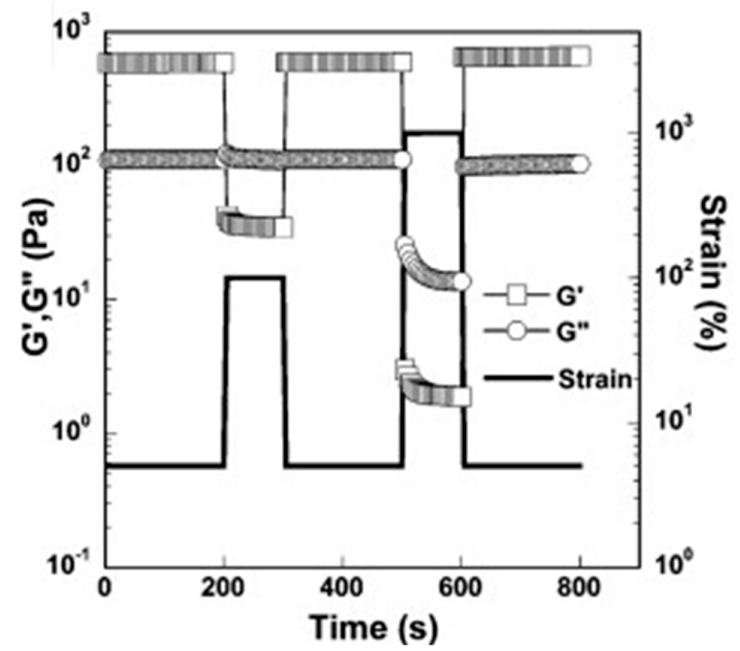

(B)

Figure 4. (A) Schematic illustration of liposome gel. Cholesterol end groups of Chol-PEG-Chol were embedded in the liposome bilayers, forming bridge, loop or dangling; (B) Evolution of storage $G^{\prime}(\square)$ and loss modulus $G^{\prime \prime}(\bigcirc)$ of liposome gel with time following two successive pulses of high deformation (solid line). Reprinted with permission from [87]. Copyright 2016 Elsevier.

\subsection{Host-Guest Interactions}

Host-guest interactions represent specific non-covalent interactions that are based on selective inclusion complexation between macrocyclic hosts, such as cucurbit[n]urils, cyclodextrins, crown ethers, calix[n]arenes, resorcinarenes, and pillar[n]arenes, and smaller guest molecules [42,88-90]. Although the size of the cavity and portal of a host molecule are good predictors of binding, the selectivity of a host towards a guest goes beyond a simple hole-fitting concept, as solvent 
effects, multiple binding sites or secondary interactions can be involved [90,91]. Self-healing gels exploiting inclusion complexation can be built by (1) mixing host- and guest-equipped polymers or (2) copolymerizing vinyl group-bearing pre-formed host-guest inclusion complexes with comonomers [42,89]. Although all the macrocycles above show potential for building self-healing gels, mainly cyclodextrins and cucurbit[n]urils have so far been used in fabricating hydrogels and will be discussed more in detail below. Crown ether derivatives have been used to fabricate linear and crosslinked supramolecular polymers owing to their affinity towards cationic species $[88,92,93]$, but self-healing has only been reported for organogels formed upon the complexation of polymer-bound cationic guests by a bis(crown ether) [94] or crown-ether-bearing polymers by bis-ammonium compounds [95].

\subsubsection{Cyclodextrins}

Cyclodextrins (CDs) are popular hosts in supramolecular chemistry owing their availability and selectivity according to the cavity size $(\gamma-C D>\beta-C D>\alpha-C D)$, where hydrophobic and van der Waals interactions between the inner surface of $C D$ ring and hydrophobic guests of suitable size are responsible for inclusion complexation [96,97]. Guest molecules can range from polar compounds such as alcohols, acids, amines, and amino acids to less polar compounds such as linear and branched alkyls, cycloalkanes, aromatic molecules, and steroidal compounds or even to polymeric molecules, such as in the case of poly(pseudo)rotaxanes [98].

Following the first strategy of mixing two functionalized polymers, self-healing gels have been prepared from $\mathrm{CD}$-bearing polymers, such as poly(meth)acrylates, poly $(\mathrm{N}$-alkyl)acrylamides, poly(ethylene glycol) or poly(ethylene imine), and guests such as ferrocene [99-102], imidazole [103], bromonaphthalene [104], and azobenzene [104]. Even larger guests can be bound, such as bile acids, which are physiologically important steroidal compounds and thus, ideal building blocks for polymeric biomaterials [105-108]. They can form inclusion complexes with $\beta-C D$ and the complexation can be inversed upon the addition of competing guest, potassium 1-adamantylcarboxylate [109]. Host-guest complexation between poly $(\mathrm{N}, \mathrm{N}$-dimethylacrylamide) chains bearing either $\beta-\mathrm{CD}(8 \mathrm{~mol} \%)$ or cholic acid moieties $(2 \mathrm{~mol} \%)$ yielded self-healing hydrogels, which showed highest storage modulus $\mathrm{G}^{\prime}$ at 1:1 host guest ratio and high polymer concentrations (12.5 wt\%). The gel elasticity was recovered rapidly (in $30 \mathrm{~s}$ ) after the shear-induced rupture of supramolecular crosslinks (Figure 5). The plateau modulus $\mathrm{G}_{0}$ of 1:1 gels was $\sim 10-1000 \mathrm{~Pa}$ at $6.5-12.5 \mathrm{wt} \%$ [63]. Another steroidal molecule, cholesterol (Chol), has been used as a guest in self-healing gels based on the inclusion complexation between poly(L-glutamic acid) (PLGA)-bound $\beta$-CD (48 mol\%) and PLGA- $b$-PEG- $b$-PLGA triblock copolymer furnished with pendent Chol groups ( $20 \mathrm{~mol} \%$ ) [110]. The healing time of these gels was $60 \mathrm{~s}$, determined by oscillatory step strain experiments, and high compressive modulus (46 kPa) was obtained with a high-molar-mass linker with long PLGA blocks ( $\sim 30 \mathrm{kDa})$. The gels showed good biocompatibility and slow degradation of up to 72 days in vitro at $37^{\circ} \mathrm{C}[110]$.

Self-healing can also be achieved through reversible polypseudorotaxane formation, which involves binding of a polymer chain inside several polymer-bound macrocyclic hosts. Complexation between $\beta$-CD-grafted alginate (Alg-g-CD) and Pluronic ${ }^{\circledR} 108$ yielded self-healing biocompatible and degradable hydrogels (Figure 6), where multiple cyclodextrin hosts bound to the middle block of Pluronic PEG- $b$-PPG- $b$-PEG triblock copolymer (PPG = poly(propylene glycol)) [111]. Rapid recovery from shear (in $10 \mathrm{~s}$ ) was observed and the gels remained stable over long periods of time (up to 5 days). As Pluronic ${ }^{\circledR} 108$ is thermosensitive, forming micelles at body temperature, the association of the $\beta$-CD-bound block copolymer upon increasing temperature led to significant stiffening of gels and the strongest gels showed elastic shear modulus $G^{\prime}$ of $10-12 \mathrm{kPa}$ at $f=10 \mathrm{~Hz}$. The gels exhibited gradual release of a globular protein of $66.5 \mathrm{kDa}$ (bovine serum albumin, BSA) in vitro and thus, applications as injectable delivery vehicles were proposed [111]. 


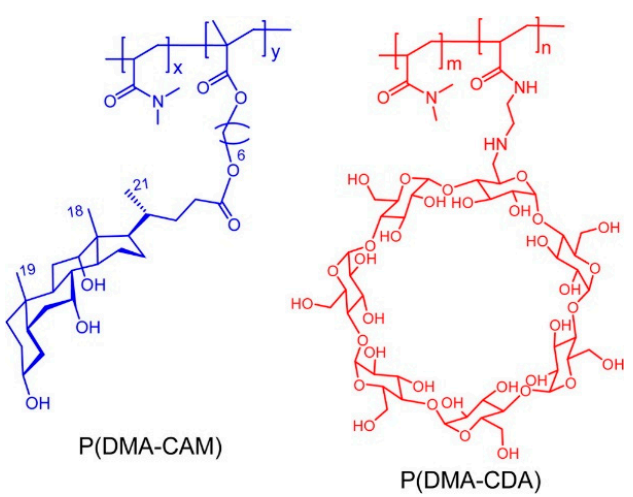

(A)

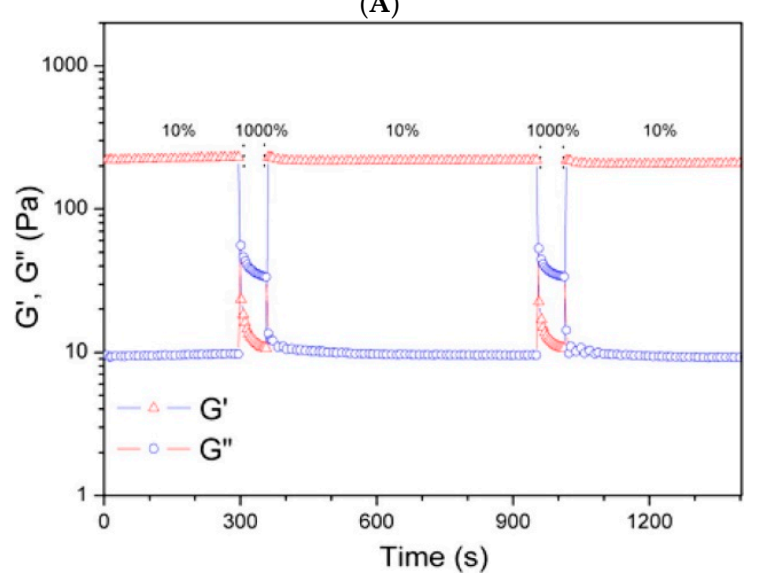

(B)

Figure 5. (A) Structures of cholic acid- (left) and $\beta$-CD-bearing (right) poly( $N, N$-dimethylacrylamides), $\mathrm{P}(\mathrm{DMA}-\mathrm{CAM})$ and P(DMA-CDA), respectively; (B) $\mathrm{G}^{\prime}$ (squares) and $\mathrm{G}^{\prime \prime}$ (circles) values of the $\mathrm{P}(\mathrm{DMA}-\mathrm{CAM}-2 \%) / \mathrm{P}(\mathrm{DMA}-\mathrm{CDA})$ hydrogel $(8.3 \mathrm{wt} \%)$ in continuous step strain measurements $\left(25^{\circ} \mathrm{C}\right)$. Large strain $(1000 \%)$ inverted the values $G^{\prime}$ and $G^{\prime \prime}$ to give the sol state. $G^{\prime}$ was recovered under a small strain $(10 \%)$ within $30 \mathrm{~s}$. Reprinted with permission from [63]. Copyright 2016 American Chemical Society.
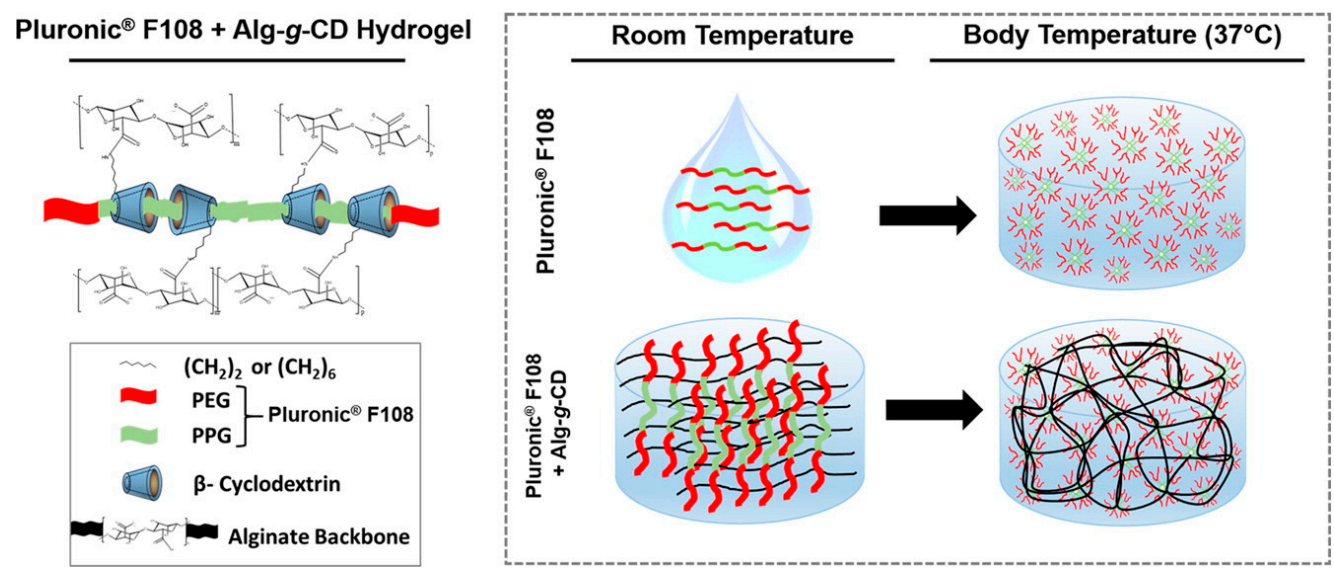

Figure 6. Physical cross-linking between Alg- $g$-CD macromolecules and Pluronic ${ }^{\circledR}$ F108 (left) and the thermo-response of the hydrogel network (right). Pluronic ${ }^{\circledR}$ F108 forms micelles and self-cross-links at body temperature. $\beta-\mathrm{CD}$ (host) conjugated onto the alginate backbone (Alg-g-CD) formed a physically cross-linked supramolecular inclusion complex with the guest, the PPG block (green) of Pluronic ${ }^{\circledR}$ F108. Reprinted with permission from [111]. Copyright 2016 American Chemical Society. 
The host and guest moieties can also coexist in the same polymer. Harada group prepared a series of tough and flexible self-healing gels from a variety of polyacrylamides and polyacrylates, where $\beta-C D$ and adamantane were side groups of the same polymer chain, leading to interpolymer interactions and thus crosslinking [112]. High host and guest content in the same chain led to poorer mechanical properties through the heterogeneity of the resulting network. The polymers showed potential as self-healing coatings in the dry state, where healing through supramolecular interactions could be induced upon exposing the damaged area to water that acts as a plasticizer and increases the mobility of the polymer chains. The synthetic approach was taken even further in redox-sensitive self-healing gels based on polyacrylamides furnished with the abovementioned $\beta$-CD and Ad units as well as a ferrocene side group, which can be bound to $\beta-C D$ in its reduced state but expelled in oxidized form (Figure 7) [113]. The strongest gels based on $\beta$-CD-Ad-Fc-PNIPAAm achieved Young's modulus $\mathrm{E}$ of up to $20 \mathrm{kPa}$, obtained by tensile testing. Self-healing occurred in both oxidized and native states although the healing efficiency was lower for the oxidized gel. Here, the self-healing took at least $2 \mathrm{~h}$ and $70 \%$ recovery ratio was achieved for native gel in $>70 \mathrm{~h}$. Oxidization also led to gel swelling due to reduced crosslinking density. Interestingly, the gels showed also a shape memory effect based on the release of $F_{C}$ upon oxidation and rebinding to a new $\beta$-CD site upon reduction [113].

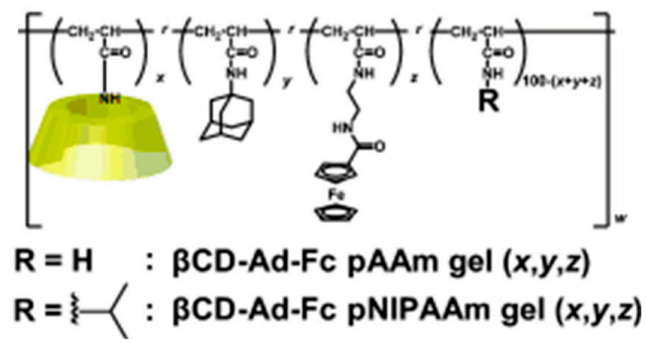

(A)

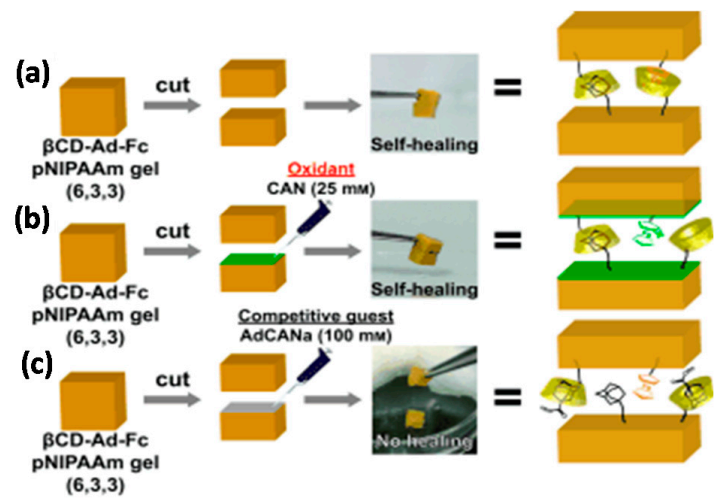

(B)

Figure 7. (A) Structures of copolymers bearing $\beta-C D$, adamantane (Ad) and ferrocene $\left(F_{c}\right)$ in the same chain; $x, y$ and $z$ indicate $\mathrm{mol} \%$ of respective units in the chain; (B) Self-healing properties of a poly( $\mathrm{N}$-isopropylacrylamide) copolymer (a) with Fc in reduced form; (b) Fc in oxidized form; and (c) in the presence of competitive guest sodium adamantanecarboxylate (AdCANa). Reproduced with permission from [113]. Copyright 2016 John Wiley and Sons.

Figure 8 presents an example of the second type of preparation strategy for self-healing supramolecular gels, where host-guest complexes are formed prior to the copolymerization of host $(\alpha-C D$ or $\beta-C D)$ and guest (adamantane, Ad or n-butyl, $n-B u$ ) molecules that both bear polymerizable vinyl groups [114].The aim was to improve the self-healing capacity upon preorganization of interacting domains. Greater degree of self-repair was obtained with Ad guest ( $99 \%$ after $24 \mathrm{~h}$, bound to $\beta-\mathrm{CD})$ than with n-Bu $(74 \%$ after $24 \mathrm{~h}$, bound to $\alpha-\mathrm{CD})$ and the elastic modulus $\mathrm{G}^{\prime}$ of $\beta$-CD-Ad gel was $100-1000$ times higher than that of $\alpha-C D-n B u$ gel $(680 \mathrm{kPa}$ vs. $0.33 \mathrm{kPa})$. Self-healing of the former gel could be prevented upon adding a competitive guest, sodium adamantanecarboxylate (AdCANa), or free host, $\beta$-CD [114]. 


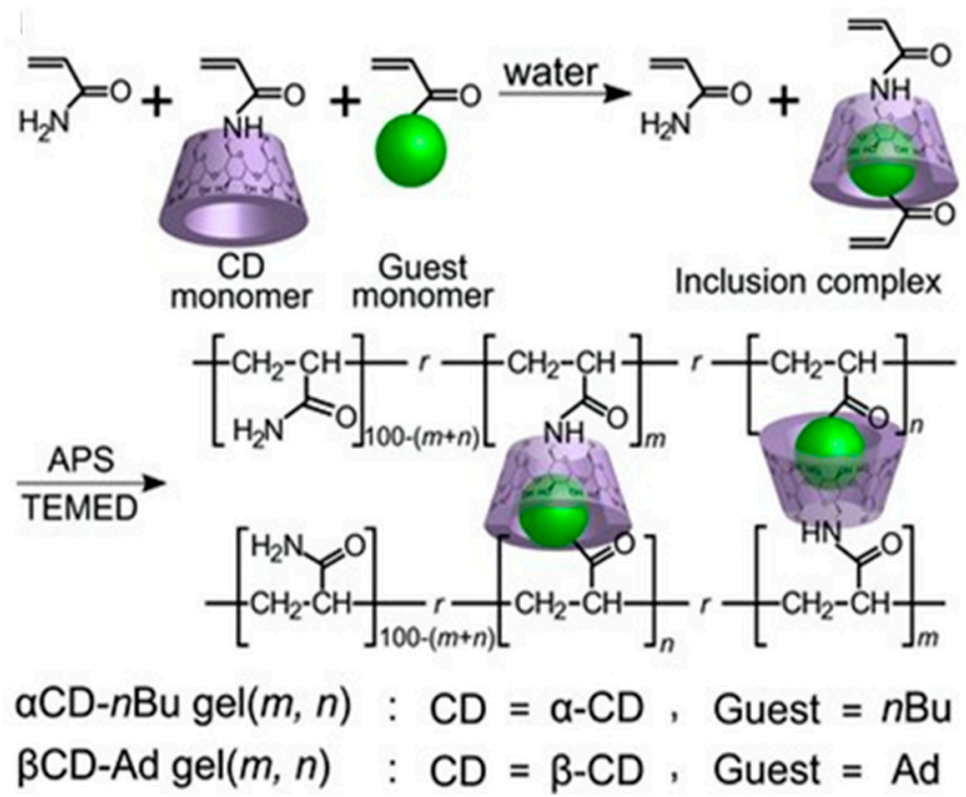

Figure 8. Preparation of host-guest supramolecular $\alpha \mathrm{CD}$-nBu gels $(m, n)$ and $\beta C D$-Ad gels $(m, n)$; $m$ and $n$ denote the $\mathrm{mol} \%$ of the host unit and guest unit, respectively. Reprinted with permission from [114]. Copyright 2016 John Wiley and Sons.

\subsubsection{Cucurbit[n]urils}

Macrocycles composed on glycouril units, cucurbit[n]urils (CB[n], where $n=5-8,10 ; n=6$ most abundant), can form binary 1:1 or ternary 1:1:1 host-guest complexes with a variety of guest molecules. A comprehensive review of guests of $\mathrm{CB}[\mathrm{n}]$ was recently published by Scherman et al. [115]. The cavity of $\mathrm{CB}[8]$ is large enough to accommodate two guests, and ternary complexes can be formed upon simultaneous binding of an electron-rich and an electron-deficient guests, such as naphthyl and methylviologen derivatives, respectively $[116,117]$. Because the functionalization of cucurbit[n]urils can be challenging $[118,119]$, inclusion complexation-induced crosslinking and gelation is rather achieved upon ternary binding of polymer-bound guests by free $C B[n]$ [120-122].

Self-healing hydrogels were prepared from naphthyl-functionalized hydroxyethyl cellulose (HEC-Np) and a viologen-functionalized poly(vinyl alcohol) (PVA-MV) [121]. The latter gels were reinforced by adding colloidal nanofibrillated cellulose (NFC) hydrogel to a fixed composition of supramolecular HEC-Np/PVA-MV/CB[8] hydrogel. Figure 9 depicts the resulting interpenetrating network (IPN). Supramolecular hydrogel alone showed rapid and complete self-healing after repeated shear, owing to rapid association kinetics of the ternary complex of $\mathrm{CB}[8]$ (association constant $k_{\mathrm{a}} \sim 10^{8} \mathrm{M}^{-1} \cdot \mathrm{s}^{-1}$ ) [121]. The strongest hybrid hydrogel has elastic modulus $\mathrm{G}^{\prime}$ of $2 \mathrm{kPa}$ at $0.1 \%$ strain and it was stronger (up to 50 -fold increase in $G^{\prime}$ ), had higher yield strain (up to $>4$-fold enhancement) and showed improved and faster structure recovery than NFC gel alone. Supramolecular HEC-Np/PVA-MV/CB[8] hydrogel bridged the denser floc-like domains of colloidal NFC gel and mediated the healing of NFC network [122]. The recent research on ternary CB[n] complexes $[115,123-125]$ gives promise to further developments in self-healing host-guest materials. 
A) Supramolecular hydrogel

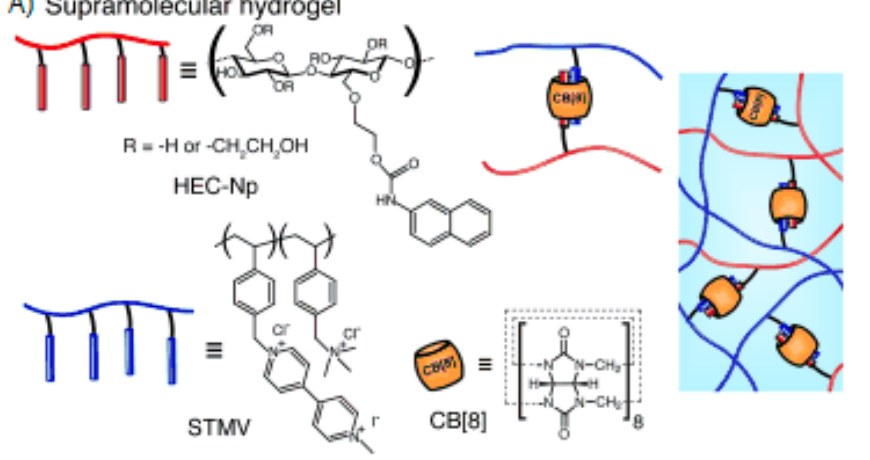

B) Colloidal reinforcing hydrogel
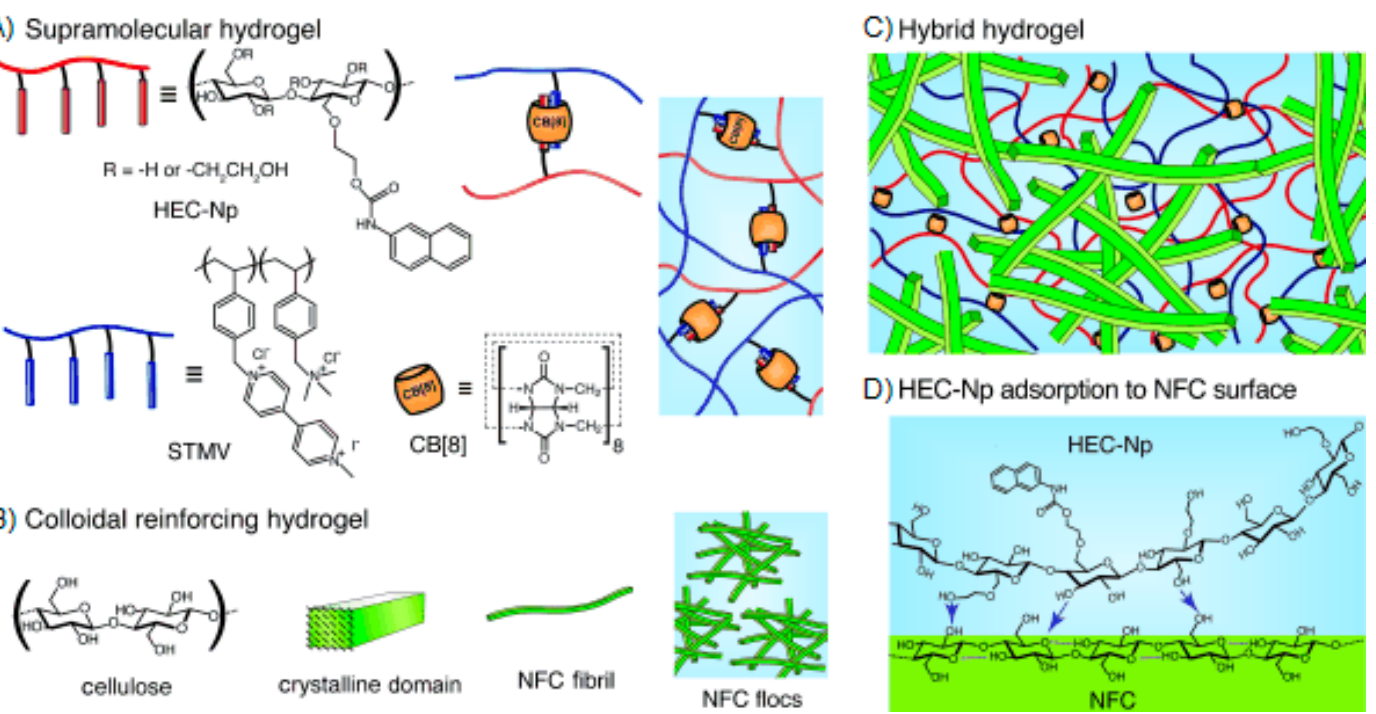

D) HEC-Np adsorption to NFC surface

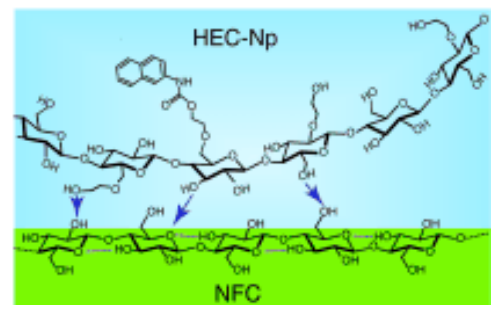

Figure 9. (A) Supramolecular hydrogel consisting of HEC-Np, STMV, and the CB[8] host motif capable of binding the first guest naphthyl and the second guest viologen highly dynamically; (B) Colloidal reinforcing nanofibrillated cellulose, also showing the denser and less dense network regimes; (C) Interpenetrating hybrid hydrogel consisting of the molecular-level supramolecular and colloidal-level NFC hydrogel; and (D) Surface adsorption of HEC-Np onto the NFC surface. Possible hydrogen bonding is schematically shown. Reprinted with permission from [122]. Copyright 2016 John Wiley and Sons.

\subsection{Hydrogen Bonding}

Dynamic supramolecular polymers are typically synthesized by introducing complementary H-bonding donor and acceptor motifs into the building blocks $[65,66,126]$, which is also an elegant strategy for building reversible networks with self-healing capacity. In aqueous medium, the H-bonding occurs in competition with water molecules, whose contribution can be diminished by using multiple H-bonding motifs with high dimerization affinity, such as 2-ureido-4[1H]pyrimidinone (UPy) units. The dimerization can be further enhanced by shielding the motifs from water with hydrophobic substituents, such as adamantyl (Ad) or alkyl groups [127]. Such motifs have been used to induce reversible physical network formation of a copolymer of $N, N^{\prime}$-dimethylacrylamide (DMA) and a methacroyl monomer bearing a Ad-functionalized UPy unit [127] or a PEG chain bearing UPy moieties shielded from water by apolar isophorone [128] or alkyl spacers $[129,130]$ (Figure 10a,b). The transient network formation of telechelic UPy-bearing polymers arose from the entanglement of supramolecular self-assembled fibrils at elevated concentrations (Figure 10c), which was further dependent on the length of the alkyl spacer and temperature [129]. These hydrogelators showed a reversible transition from viscous liquids to solid-like gels upon cooling, and the gel strength and self-healing properties could be modulated by the addition of short-chain monofunctional UPy-PEGs [130]. The strongest gel showed elastic modulus $\mathrm{G}^{\prime}$ of $18 \mathrm{kPa}$ at $20^{\circ} \mathrm{C}$ at angular frequency of $10 \mathrm{rad} / \mathrm{s}$. Despite the multivalency of interactions, the structure recovery of the gels could take from hours to days, similar to many low-molecular-weight hydrogelators (LMWHs) that also form networks of bundled self-assembled fibers, studied extensively by the groups of Weiss, van Esch, and Zhu, among others [131-134]. The slow recovery raises a question of whether such systems can be strictly considered as self-healing materials, as rapid healing and fast macromolecular dynamics are often required for potential applications. Nevertheless, the transient network formation of telechelic UPy-alkyl-PEGs was fast enough for the successful encapsulation and injection delivery of an anti-fibrotic growth factor protein BMP7 in vivo in the kidney capsule of rats [129]. 


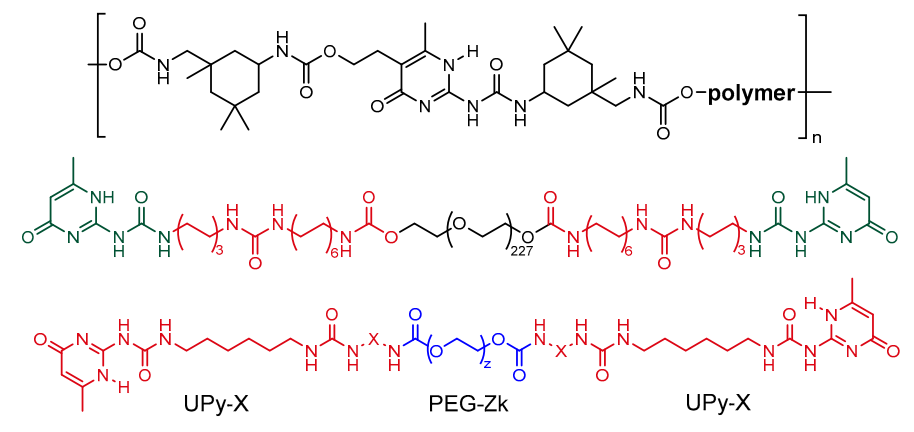

(A)

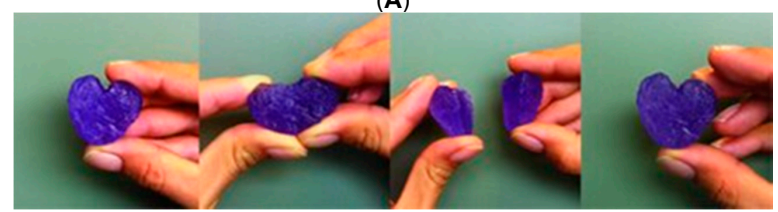

(B)

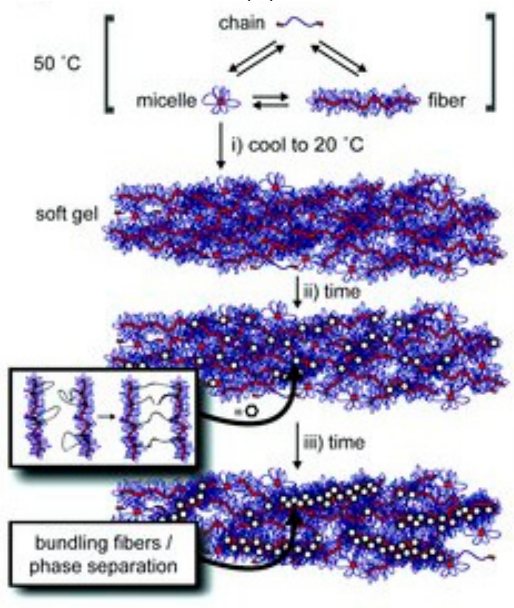

(C)

Figure 10. (A) Examples of the structures of PEG-based H-bonding polymers that contain UPy units as part of main chain [128] or as end groups [129,130]; (B) Visual demonstration of the self-healing of a $15 \mathrm{wt} \%$ hydrogel of the main-chain-functionalized polymer of (a). Purple dye was added for demonstration purposes [128]; (C) At high temperatures (above $50{ }^{\circ} \mathrm{C}$ ) and in dilute solution, the hydrogelators are present as three species: single chain, spheric micelle, and fiber: (i) Upon cooling, or increase in concentration, a soft hydrogel is formed; (ii) After a time span of approximately 16-24 h, the strength of the gel is increased due to the formation of supramolecular cross-links; and (iii) The fibers may bundle and phase separate forming ordered domains in the hydrogel network. Reprinted with permissions from [128,129]. Copyright 2016 John Wiley and Sons. 


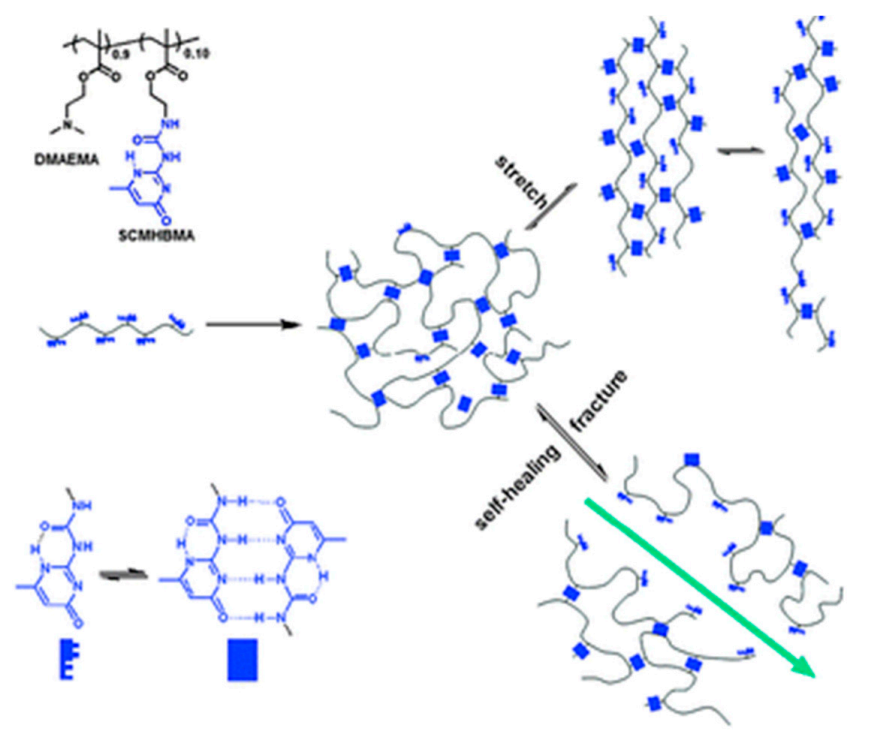

(A)

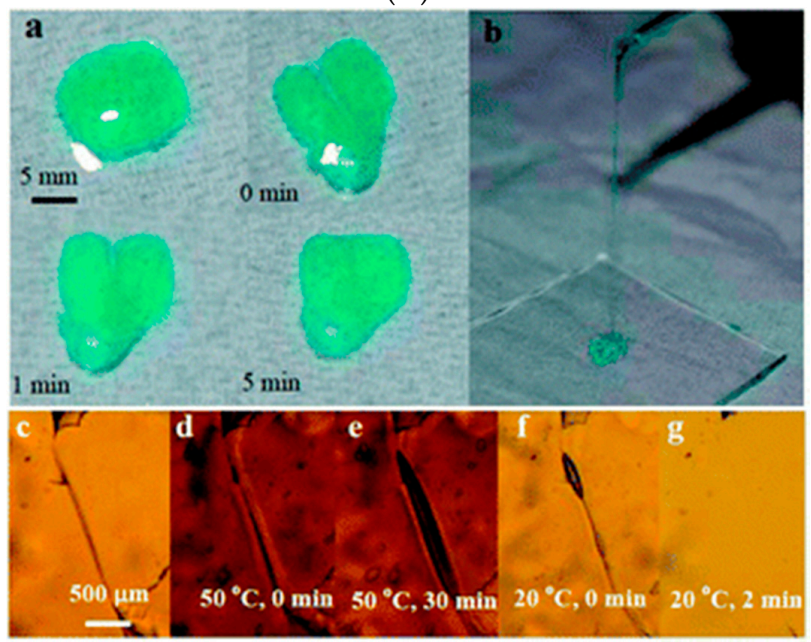

(B)

Figure 11. (A) Chemical structure of the copolymer containing DMAEMA and SCMHBMA and the schematic model of self-healing and stretching of the hydrogel formed by the copolymer; (B) Demonstration of the self-healing $(\mathbf{a}, \mathbf{c}-\mathbf{g})$ and the stretching $(\mathbf{b})$ properties of the DMAEMA-SCMHBMA hydrogel at $\mathrm{pH}$ 8. The gel in $(\mathbf{a}, \mathbf{b})$ was colored with methyl blue for better imaging. Optical microscopy images $(\mathbf{c}-\mathbf{g})$ were obtained from a hydrogel film with an incision (c) after annealing at $50{ }^{\circ} \mathrm{C}(\mathbf{d}, \mathbf{e})$ and subsequent cooling to $20^{\circ} \mathrm{C}(\mathbf{f}, \mathbf{g})$. Reprinted with permission from [135]. Copyright 2016 Royal Society of Chemistry.

UPy units can also be introduced as side groups that form interchain crosslinks upon H-bonded dimerization. A copolymer composed of 2-(dimethylamino)ethyl methacrylate (DMAEMA) and a UPy-unit-bearing monomer 2-(3-(6-methyl-4-oxo-1,4-dihydropyrimidin-2-yl)ureido)ethyl methacrylate (SCMHBMA) (Figure 11A) was thermo-responsive with lower critical solution temperature (LCST) of $40{ }^{\circ} \mathrm{C}$ at $\mathrm{pH} 8$ [135]. The copolymer yielded viscous solutions at acidic $\mathrm{pH}$ where DMAEMA units were protonated, whereas self-healing hydrogels were obtained at neutral to basic $\mathrm{pH}(\mathrm{pH} 7-8)$ at $20^{\circ} \mathrm{C}$ (Figure 11B). Here, the self-healing properties were only observed visually and using polarized optical microscopy (POM). Increasing the temperature above the LCST prevented self-healing, because the collapse of polymer chains restricted their diffusion to the damaged site and $\mathrm{H}$ bonds could not be restored. Self-healing was also observed for covalently crosslinked gels with the same composition, as well as for other copolymers of SCMHBMA with hydrophilic or thermo-sensitive comonomers, 
such as 2-hydroxyethyl methacrylate (HEMA), 2-(2-methoxyethoxy)ethyl methacrylate (MEO2MA), $N$-isopropylacrylamide (NIPAAm), and $N, N^{\prime}$-dimethylacrylamide (DMA) [135]. Later, this monomer was copolymerized into crosslinked polyurethane-PEG-methacrylate (PU-PEGMA) networks to yield highly deformable (elongation at break up to $2000 \%$ ) self-healing hydrogels, which were capable of recovering up to $87 \%$ of their original tensile strength of $382 \mathrm{kPa}$ in $10 \mathrm{~min}$ after bringing the cut pieces into contact. The gels also showed high compression strength of up to $4.5 \mathrm{MPa}$ and did not rupture even when exposed to $90 \%$ compressive strain [136].

Varghese and coworkers [137] showed that poly(6-acryloyl-6-aminocaproic acid)-based hydrogels (PA6ACA) underwent rapid $(<2 \mathrm{~s})$ and repeatable $\mathrm{H}$-bonding-induced self-repair in acidic conditions $(\mathrm{pH} \leqslant 3)$ where carboxylic acid groups were protonated. A6ACA monomer contains an alkyl spacer between the acrylamide and - $\mathrm{COOH}$ group. The hydrogels healed for $10 \mathrm{~s}$ could withstand higher than $2 \mathrm{kPa}$ tensile stresses and the rupture occurred within the bulk region of the gel, not at the welded interface. The self-healing ability depended strongly on the availability of amide bond for H-bonding, that is, the length of the spacer between $-\mathrm{COOH}$ and amide group. Based on proof-of-concept testing, the gels are expected to find their applications as acid-resistant sealants, muco-adhesive tissue adhesives and drug delivery vehicles, and soft structures for various devices [137]. Self-healing of these gels could also be induced by divalent metal complexation $\left(\mathrm{Cu}^{2+}\right)$ by A6ACA units [138]. Recently, the copolymers of an amino acid-based monomer, $N$-acryloyl glycinamide (NAGA) and acrylamide (AAm) showed thermoplasticity and temperature-driven $\mathrm{H}$-bonding between the amino acid moieties, which yielded strong self-healing hydrogels ( $\mathrm{G}^{\prime}$ up to $1 \mathrm{MPa}$ ) with the healing efficiency of up to $84 \%$ [139].

\subsection{Ionic Interactions}

Ionic interactions have long been used to reinforce elastomeric materials, as a relatively small concentration of acid or ionic groups can substantially alter the physical, mechanical, optical, dielectric, and dynamic properties of a polymer $[140,141]$. Ionomers, i.e., copolymers with typically less than 15 $\mathrm{mol} \%$ of ionic groups, and polyelectrolytes are widely used to create ionic supramolecular systems and crosslinked networks [141]. For example, self-healing materials based on non-aqueous ionic networks have been made from poly(acrylic acid) (PAA) and a phosphonium ionic liquid linker, where the length of the alkyl substituents and number of phosphonium groups (di- or monofunctional) determined the mechanical properties of the material [142]. Ionic crosslinks can also be used to dissipate energy and induce healing of covalently crosslinked hydrogels. For instance, tough stretchable hydrogels have been synthesized by mixing ionically crosslinked alginate (crosslinking by $\mathrm{Ca}^{2+}$ ions) into a photocrosslinked polyacrylamide (PAAm) network. These gels were stronger than individual PAAm or alginate gels and stretchable to nearly 20 times of their length prior to rupture. Of the network strength, $74 \%$ was recovered after 1 day of healing at elevated temperature $\left(80^{\circ} \mathrm{C}\right)$ [143].

The interacting charges may also exist in the same monomer. Zwitterions are dipolar species, in which the cation and the anion are separate in the same monomer unit and can be completely dissociated, thus maintaining the overall electroneutrality. Zwitterionic polymers have been shown to form reversible self-healing hydrogels through ionic interactions. Examples of such systems are carboxy- or sulfobetaines and their copolymers with neutral comonomers. A carboxybetaine acrylate (AAZ) homopolymer yielded biocompatible rapidly healing ( $\leqslant 100 \mathrm{~s}$ ) hydrogels, where the strongest physically crosslinked gels exhibited elastic modulus $\mathrm{G}^{\prime}$ of $\sim 800 \mathrm{~Pa}$, tensile strength of around $60 \mathrm{kPa}$ and Young's modulus E of $\sim 25 \mathrm{~Pa}$. The self-healing of gels (Figure 12a) was induced by the electrostatic attraction ("zwitterionic fusion") between the quaternary ammonium group and carboxylate group of the same monomer. The self-healing could take place even after a long separation time of the cut fragments both in physically and chemically crosslinked gel samples [144], while most examples of self-healing of gels have been tested on fresh surfaces. Moreover, the fusion of cell-laden pieces of hydrogel did not cause a significant loss in cell viability, which suggests potential applications in tissue engineering and regenerative medicine. 


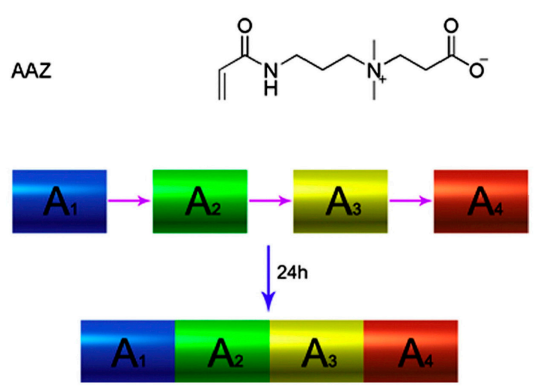

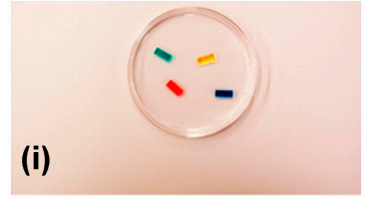

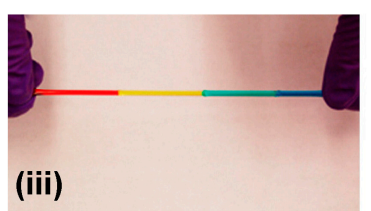

(iii)
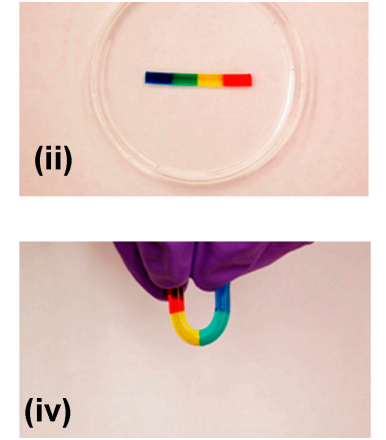

(A)

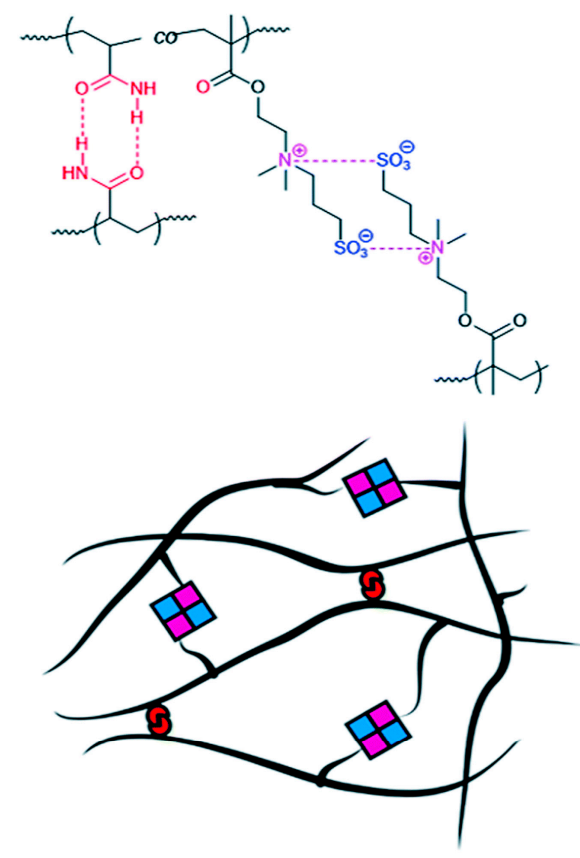

(B)

Figure 12. (A) Carboxybetaine acrylate (AAZ) monomer and the fusion of its homopolymer hydrogels from separate blocks $\left(\mathrm{A}_{1}-\mathrm{A}_{4},(\mathrm{i})\right)$ into a uniform gel (ii) that can be stretched (iii) and bent (iv) without breaking. $\mathrm{A}_{1}$ (blue), $\mathrm{A}_{2}$ (green), $\mathrm{A}_{3}$ (yellow) and $\mathrm{A}_{4}$ (red) have the same composition [144]; (B) Reversible hydrogen bonding and electrostatic interactions of a P(AAm-co-DMAPS) copolymer, resulting in crosslinked hydrogel formation. Reprinted with permissions from [144,145]. Copyright 2016 Elsevier and Royal Society of Chemistry.

In another carboxybetaine-based system, nanocomposite hydrogels were prepared by the copolymerization of a carboxybetaine methacrylamide CBMAA-3 ((3-methacryloylaminopropyl)(2-carboxyethyl)dimethylammonium-(carboxybetaine methacrylamide)) and 2-hydroxyethyl methacrylate (HEMA) in the presence of an inorganic clay, Laponite XLG [146]. Laponites are hydrophilic disk-shaped inorganic clay platelets that can be uniformly dispersed in water and act as physical crosslinkers. The presence of Laponite enhanced the mechanical properties of composite hydrogels (Young's modulus up to $80 \mathrm{kPa}$, elongation at break up to 1800\%) and reduced the water uptake of gels due to higher crosslinking density, while the higher zwitterion (CBMAA-3) content was associated with faster structure recovery [146]. These materials were proposed to act as non-fouling protein-resistant biomaterials. Interestingly, the nanocomposite hydrogels of Laponite with the copolymers of DMA and a sulfobetaine acrylamide ( $N, N$-dimethyl(acrylamidopropyl) ammonium propane sulfonate) (DMAAPS) demonstrated upper critical solution temperature (UCST) behavior with UCST of $\leqslant 9.3^{\circ} \mathrm{C}$ when DMA content was $\leqslant 10 \mathrm{~mol} \%$ [147]. The hydrogels showed self-healing behavior above but not below the UCST, similar to the H-bonded LCST network described in Section 3.3 [135], because the diffusion of dangling polymers chains across the damaged region and interactions with clay platelets were disrupted upon the collapse of chains below the UCST. Here, the strongest gel showed elastic modulus $\mathrm{G}^{\prime}$ of $\sim 1.6 \mathrm{kPa}$ at $0^{\circ} \mathrm{C}$ and $f=1 \mathrm{~Hz}$, the tensile strength below $5{ }^{\circ} \mathrm{C}$ was $\sim 65 \mathrm{kPa}$ and elongation at break was $\sim 1800 \%$. However, only $20 \%$ recovery in tensile strength was achieved after $24 \mathrm{~h}$ self-healing above the UCST [147].

Combined electrostatic and $\mathrm{H}$-bonding interactions were responsible for the self-healing of a zwitterionic hydrogel based on P(AAm-co-DMAPS) polymers, where AAm = acrylamide and DMAPS = 3-dimethyl(methacryloyloxyethyl) ammonium propane sulfonate (Figure 12b) [145]. High healing efficiency (up to $80 \%$ ) and fast recovery ( $35 \mathrm{~s}$ ) were observed for gels with AAm/DMAPS $=1$ and the 
strongest gel showed elastic modulus $\mathrm{G}^{\prime}$ of $\sim 5.5 \mathrm{kPa}$. The suggested applications of these hydrogels are in the field of enhanced oil recovery (EOR) [145].

\subsection{Polymer-Nanocomposite Interactions}

Some of the above-mentioned examples have demonstrated the use of inorganic clay nanoplatelets (Laponite) $[146,147]$ to enhance the mechanical properties of supramolecular hydrogels. Aida and coworkers [148] prepared rapidly self-healing hydrogels from aqueous clay nanosheet (CNS) solution with sodium polyacrylate (ASAP) as a dispersant and exfoliator by adding a guanidine-functionalized dendritic macromolecule (G3-binder, Figure 13). Positively charged guanidium groups adhere to anionic CNSs and act as crosslinkers, leading to strong $\left(\mathrm{G}^{\prime}>5 \mathrm{kPa}\right)$ free-standing gels which recovered repeatedly from shear-induced rupture in $600 \mathrm{~s}$. The gels could resist brine and moderately acidic and basic conditions ( $\mathrm{pH}$ 4.0-10.0) and could incorporate and maintain biologically active proteins, such as myoglobin. A myoglobin-loaded gel retained $~ 71 \%$ of the catalytic activity of myoglobin in the oxidation of $o$-phenylenediamine with $\mathrm{H}_{2} \mathrm{O}_{2}$ in phosphate buffer, suggesting potential applications in the transport of biologically active agents [148]. Guanidinium-based $\left(\mathrm{PG}_{\mathrm{n}}\right)$ blocks have also been used to build luminescent self-healing hydrogels via physical crosslinking of $\mathrm{PG}_{n}-b-\mathrm{PEO}_{230}-b-\mathrm{PG}_{\mathrm{n}}$ block copolymers with anionic nanosized inorganic transition-metal oxide clusters, polyoxometalates (POMs). The resulting self-healable hydrogels showed enhanced luminescence properties, elastic modulus $\mathrm{G}^{\prime}$ of up to $30 \mathrm{kPa}$ and rapid structure recovery in $20 \mathrm{~s}$ [149]. In another example of nanoclay composites, the interaction of a cationic PDMAEMA 6 - $b-\mathrm{PEO}_{109}-b-\mathrm{PDMAEMA}_{6}$ block copolymer with Laponite XLG clay platelets resulted in a self-healing $\mathrm{CO}_{2}$-responsive hydrogel, where protonated PDMAEMA blocks were bound to the anionic surface of nanoclay and formed interplatelet bridges. The protonation of PDMAEMA was induced by bubbling $\mathrm{CO}_{2}$ through the clay-polymer solution and it could be reversed by $\mathrm{N}_{2}$ flow, while the self-healing of the gel arose from the electrostatic interactions. The strongest gel showed elastic modulus $\mathrm{G}^{\prime}$ of $5 \mathrm{kPa}$ at $f=1 \mathrm{~Hz}$ [150]. The interaction with nanoclay could also be based on H-bonding, such as in the case of self-healing Laponite nanoclay composites with water-soluble poly $\left(N, N^{\prime}\right.$-dimethylacrylamide $)$ (PDMA) or thermo-responsive poly( $N$-isopropylacrylamide) (PNIPAAm) [151].

Self-healing hydrogels based on hydrophobic interactions between a hydrophobically modified water-soluble polymer and graphene oxide (GO) sheets were prepared by the copolymerization of stearyl methacrylate and acrylamide in the presence of GO and sodium dodecyl benzene sulfonate (SDBS) [74]. As discussed in Section 3.1, hydrophobically modified copolymers alone can show self-healing properties. Here, the GO sheets acted as physical crosslinking junctions resulting in a dramatic increase in mechanical strength but decreased self-healing efficiency (53\% and $66 \%$ with $5 \mathrm{wt} \%$ GO and without GO, respectively). The strongest gels exhibited tensile strength of $243 \mathrm{kPa}$ with elongation at break of $1700 \%$ and elastic modulus of $\sim 65 \mathrm{kPa}$. The nanocomposite gels could efficiently remove hydrophobic compounds from water, tested by the absorption and release of methylene blue (MB) and congo red (CR) dyes, and could be recycled cyclically for dye absorption without compromising the mechanical properties. Hence, applications in water purification have been suggested [74]. Other self-healing GO nanocomposites have been made for example from chitosan via ionic interactions between cationic chitosan and the anionic surface of GO sheets [152] or poly(6-acryloyl-6-aminocaproic acid) (PA6ACA) in the presence of $\mathrm{Ca}^{2+}$ via combined coordination and H-bonding interactions [153]. 


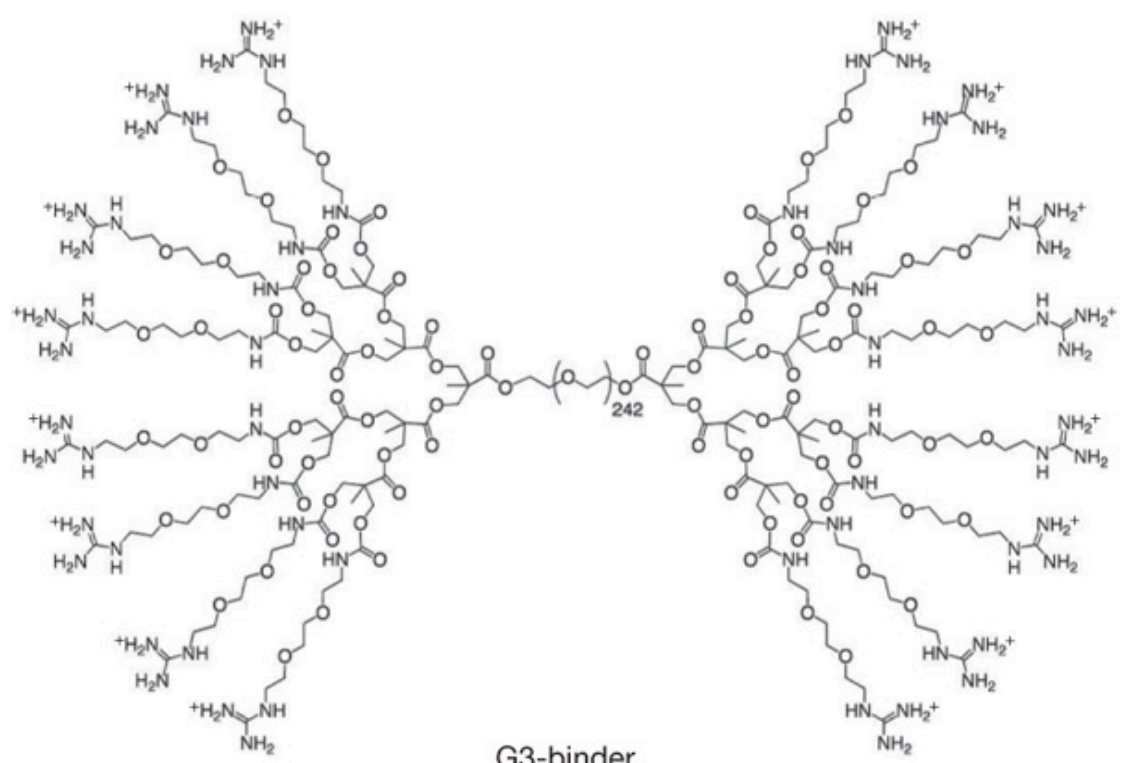

(A)

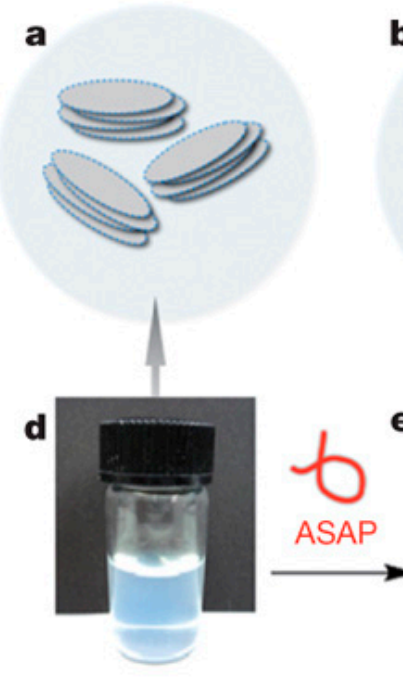

b
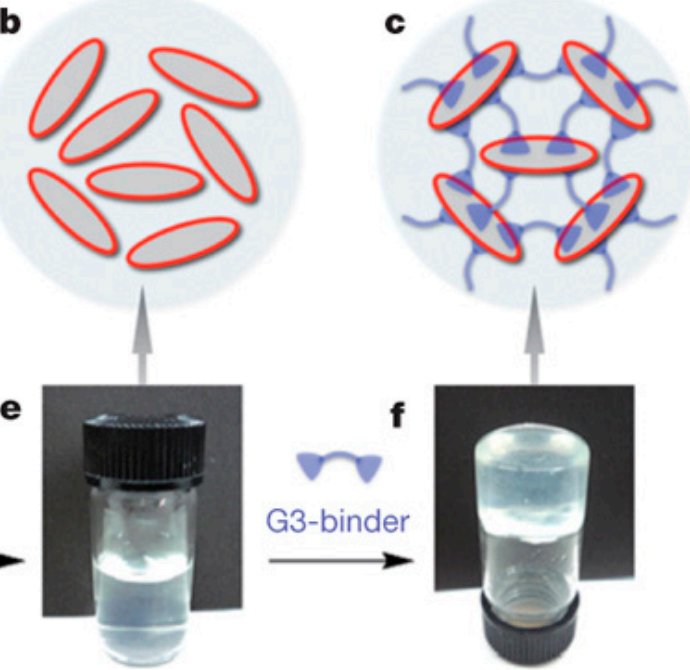

(B)

Figure 13. (A) Structure of guanidine-functionalized G3-binder; (B) Non-covalent preparation of hydrogels. $(\mathbf{a}-\mathbf{c})$ Proposed mechanism for hydrogelation. CNSs, entangled with one another (a), are dispersed homogeneously by interaction of their positive-charged edge parts with anionic ASAP (b). Upon addition of Gn-binder, exfoliated CNSs are crosslinked to develop a 3D network (c). (d-f) Optical images of an aqueous suspension of CNSs (d), an aqueous dispersion of CNSs and ASAP (e) and a physical gel upon the addition of G3-binder to the dispersion (f). Reprinted with permission from [148]. Copyright 2016 Nature Publishing Group.

\subsection{Other Crosslinking Mechanisms: Crystallization, Transient Protein Interactions}

Crystallization of macromolecules can lead to gelation in aqueous solution through locking of the polymer chains into regular structures that act as physical crosslinks. Such molecular assembly is typical for protein- or peptide-based systems [68,154,155], but is not uncommon even with synthetic macromolecules. For example, poly(vinyl alcohol) (PVA) formed physically crosslinked self-healing hydrogels when exposed to repeated freeze-thaw cycles, and the crystallinity as well as the mechanical strength of gels increased with polymer concentration and the number of cycles [73]. PVA gels of $35 \mathrm{wt} \%$ showed repeatable rapid healing and evolution of fracture stress: after $10 \mathrm{~s}$ 
recovery, the gels could withstand a stress of around $10 \mathrm{kPa}$ and after $1 \mathrm{~h}, 40 \%$ of initial tensile strength was regained. The crystallites act as physical crosslinks in a hydrogel, while self-healing is favored by concentration-dependent interchain $\mathrm{H}$-bonding and the diffusion of PVA chains over the fractured surface. Hence, self-healing could not occur below a limiting concentration $(20 \mathrm{wt} \%)$ [73]. The mechanical properties of PVA hydrogels were further enhanced by the addition of H-bonding agent, melamine, that acts as both H-bonding acceptor and donor [156].For example, a gel with $1.5 \mathrm{wt} \%$ melamine displayed a tensile strength of $3.11 \mathrm{MPa}$ and $525 \%$ elongation at break, while the values for a gel without melamine were $0.74 \mathrm{MPa}$ and $325 \%$, respectively. However, adding melamine reduced the self-healing ability PVA hydrogels (from $86 \%$ to $52 \%$ ) through increasing the gel rigidity, which further led to reduced chain interdiffusion and H-bonding over the fractured surfaces. [157]. Similarly, an interpenetrating hydrogel network of chemically crosslinked PEG and physically crosslinked PVA showed reduced self-healing capacity due to lower PVA chain mobility and lower H-bond forming -OH group density [158].

Examples of proteins and polypeptides that have been shown to form self-healing hydrogels include silk-collagen-like block copolypeptides that showed $\mathrm{pH}$-dependent fibrillar self-assembly [159], diblock copolypeptides composed of charged and hydrophobic segments that exhibited conformation-dependent ( $\alpha$-helix vs. $\beta$-sheet) gelation and high thermal stability up to $90{ }^{\circ} \mathrm{C}$ [160], micelles of elastin-like diblock copolypeptide that self-assembled into rapidly shear-recovering hydrogels upon the addition of $\mathrm{Zn}^{2+}$ [161], and bis-maleimide-PEG-linked globular actin (G-actin) that underwent reversible salt-induced self-assembly into fibrillar actin (F-actin) [162] . Pochan, Schneider and coworkers have done extensive work on self-assembling $\beta$-hairpin peptides with shear-thinning and self-healing behavior for injectable therapeutic delivery [163]. Recently, engineered peptides containing aggregation-prone and $\beta$-sheet-forming $C$-terminal amyloid $\beta$-protein sequences (associated with Alzheimer's disease) gave rise to amyloid fibril network and weak self-healing hydrogel formation $\left(\mathrm{G}^{\prime} 40-250 \mathrm{~Pa}\right.$ at $10 \mathrm{~Hz}$ ) [164]. The resulting gels recovered from deformation in $15 \mathrm{~min}$ of rest (or in $100 \mathrm{~s}$ during step strain experiments) and the recovery mechanism was associated with the stickiness of the hydrophobic surface of amyloid fibrils.

Heilshorn and coworkers [165] prepared an elegant injectable and biocompatible hydrogel that combined synthetic and peptide-based systems and underwent two different physical crosslinking mechanisms. This double network system was based on two components: (1) 8-arm star-like PEG conjugated with one thermo-responsive PNIPAAm chain and seven proline-rich peptide domains (P1); and (2) linear protein copolymer consisting of P1-recognizing units and cell adhesion-favoring RGD arginine-glycine-aspartic acid domains connected by hydrophilic spacers (Figure 14). The first crosslinking occurred ex vivo upon mixing the two components, which led to peptide-based recognition and very weak hydrogels with elastic modulus of $13 \mathrm{~Pa}$. The second crosslinking occurred at body temperature upon the collapse of PNIPAAm above its LCST and led to increase in gel strength $\left(\mathrm{G}^{\prime} \sim 100 \mathrm{~Pa}\right)$. The gels showed reversible rapid self-healing $(<2 \mathrm{~s})$ due to reformation of physical network junctions and the process was faster than with gels based on protein-ligand interactions, passive re-entanglement of polymer chains or stepwise reassembly into nanofibers. The gels enhanced stem cell retention at the desired site in vivo, reducing the number of injections and cells required for transplantation [165]. 


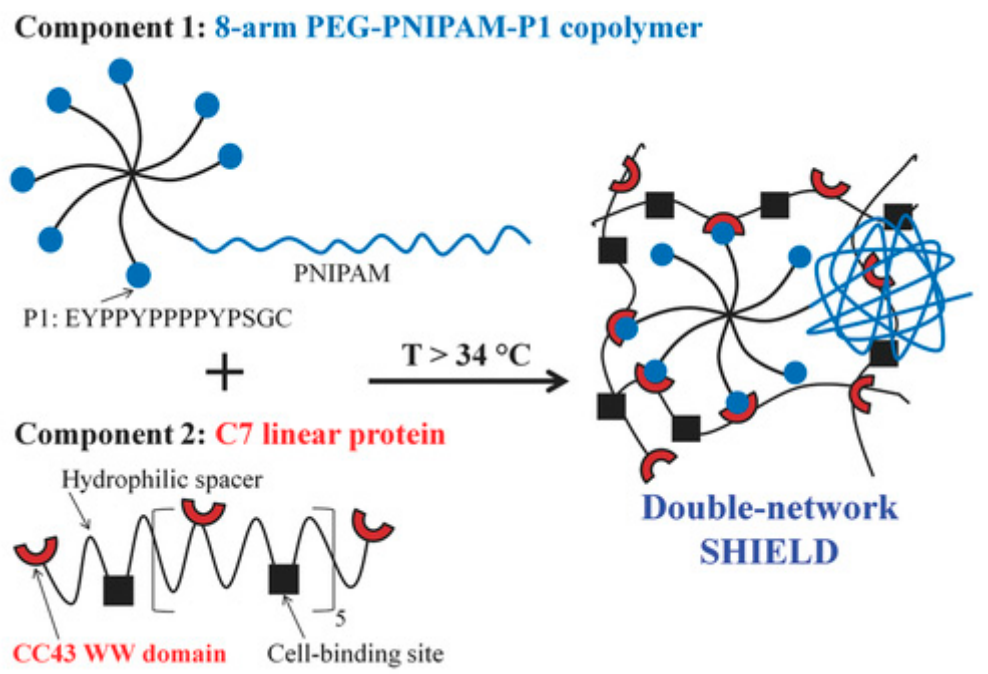

Figure 14. Schematic of a two-component double network "SHIELD", where component 1 is an 8-arm PEG with 1 arm conjugated with PNIPAAm and the other 7 arms conjugated with proline-rich peptide (denoted as P1) domains. Component 2 is a recombinant C7 linear protein copolymer bearing CC43 WW (denoted as C) domains and RGD (arginine-glycine-aspartic acid) cell-binding domains connected by hydrophilic spacers. The formation of double network occurs via peptide recognition and collapse of thermo-responsibe PNIPAAm chains. Reprinted with permission from [165]. Copyright 2016 John Wiley and Sons.

\section{Potential Applications}

Rapid shear thinning or solid-liquid transition and fast structure recovery are key requirements both for injectable hydrogels and hydrogel inks for additive manufacturing. Additive manufacturing technologies, such as 3D printing, enable the fabrication of complex micrometer- and millimeter-scale structures, where hydrogels can be used as "bio-inks" to form constructs that replace, augment or model tissues [166-169]. The strategies and molecular design criteria of 3D-printable hydrogel inks have been highlighted in a recent review, where non-covalent gelators were categorized into supramolecular polymers, low molecular weight gelators, and macromolecular and colloidal solid particle-based systems [169]. Among these, the naturally occurring, slightly modified biopolymers have so far shown the highest potential for biofabrication owing to their favorable biocompatibility and capability to support cell survival and differentiation in culture. For example, Burdick and coworkers [170] used host-guest complexation-based self-healing gels to construct patterned multicellular structures (Figure 15), where mesenchymal stem cells (MSCs) and 3T3 fibroblasts loaded within a biocompatible network of adamantane- and $\beta$-CD-functionalized biopolysaccharide, hyaluronic acid (HA), were successfully printed to their own compartments. Here, a strong $4 \mathrm{wt} \%$ HA gel with $40 \mathrm{~mol} \%$ of $\beta-\mathrm{CD}$ (host) and Ad (guest) units was used as a support gel $\left(\mathrm{G}^{\prime} \sim 1 \mathrm{kPa}\right.$ at $\left.f=1 \mathrm{~Hz}\right)$ and softer $5 \mathrm{wt} \%$ shear-thinning gel with $25 \mathrm{~mol} \%$ of host and guest units was used as an ink $\left(\mathrm{G}^{\prime \prime}>\mathrm{G}^{\prime}\right.$ at $f=1 \mathrm{~Hz}$ indicating liquid-like behavior; $\mathrm{G}^{\prime} \sim 300 \mathrm{~Pa}$ and $\mathrm{G}^{\prime}>\mathrm{G}^{\prime \prime}$ below $1 \%$ strain indicating solid-like behavior). Cyclodextrins have widely been used in numerous injectable hydrogels owing to their excellent biocompatibility, weak immunogenicity, and selectivity as supramolecular hosts $[44,171]$. Secondary covalent crosslinking was introduced via photopolymerization of pendent methacrylate groups (Me-HA) to stabilize the printed gel against chemical or physical perturbations, such as perfusion for the convection of nutrients and removal of cell metabolic waste. As a result, the gels showed increased elastic moduli $\left(\mathrm{G}^{\prime}>10 \mathrm{kPa}\right)$ and reduced frequency dependence [170]. Spatially controlled bioprinting of multiple cell types enables the development of organ or tissue constructs that do not require substantial vascularization as well as mini-tissue models for pharmaceutical or cosmetic testing and disease studies [172]. 

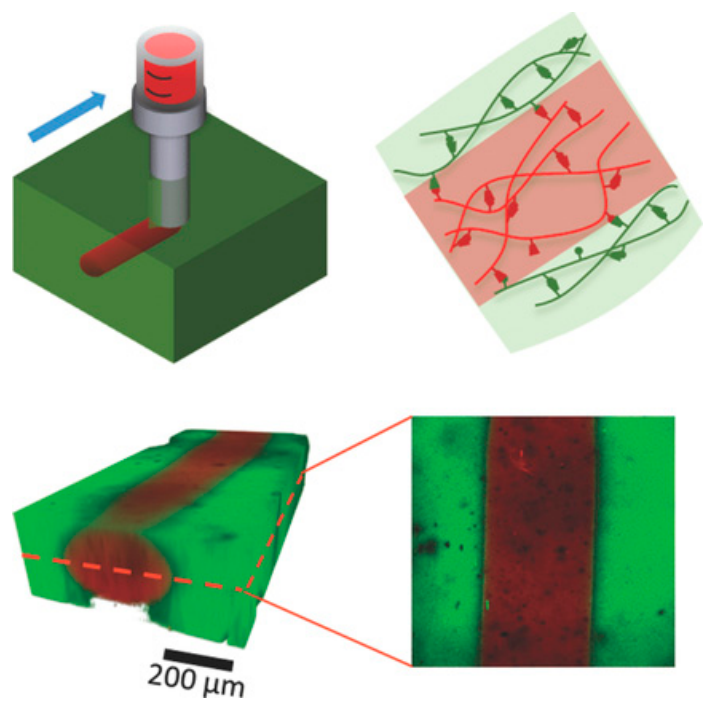

Figure 15. (Above): Schematic illustration of 3D printing of a supramolecular gel based on adamantane (Ad, guest) and $\beta$-cyclodextrin ( $\beta-C D$, host) conjugated to hyaluronic acid (HA). Green represents a supramolecular support gel and red the printed ink; (Below): 3D reconstruction of a confocal Z-stack of an ink filament (rhodamine-labeled, red) printed into a support gel (fluorescein-labeled, green). Scalebar: $200 \mu \mathrm{m}$. Reprinted from with permission [170]. Copyright 2016 John Wiley and Sons.

The use of injectable hydrogels provides a minimally invasive strategy for the administration of bioactive molecules and cells in the body $[8,173,174]$. Simple injection instead of a complicated surgical procedure reduces the infection risks and recovery time in patients and injections can be done to sites that are hard to reach by surgical techniques. Hydrogels can protect protein-based drugs from enzymatic degradation and provide targeted delivery and prolonged release of the drug to the target site [174]. They also provide a specific biological and mechanical three-dimensional environment for cells that guides the regulation of cellular functions during the formation of regenerated tissue. Injection delivery can be done via a syringe or via a catheter and recently, an H-bonded UPy-unit containing hydrogels loaded with a small-molecule drug pirfenidone or a fluorescent model protein mRuby2 were injected into a pig heart via an intramyocardial catheter [175]. The injectable system was a Newtonian fluid with low viscosity at high $\mathrm{pH}$ and formed a stiff gel with $\mathrm{G}^{\prime}=10-20 \mathrm{kPa}$ (at angular frequency $\omega=0.1-100 \mathrm{rad} / \mathrm{s}$ ) after neutralization. Here the liquid-like behavior was necessary for the delivery via a catheter. The gradual degradation of the supramolecular gel and release of the model protein shows promise of these self-healing gels as delivery systems for growth factors and exosomes. In cellular therapy, rapid self-healing of the hydrogel localizes the cells to the targeted area and increases the probability of cell retention after transplantation [165]. The above-mentioned supramolecular $\mathrm{HA} / \beta-\mathrm{CD} / \mathrm{Ad}$ hydrogel provided improved delivery and retention of endothelial progenitor cells (EPCs) in vivo in ischemic myocardium, aiming at the revascularization of myocardium after heart failure. Significant increase in the vascularization, improvement of ventricular function, and reduction of scar formation were observed [176]. Here, both examples of therapies target at the regeneration of ischemic myocardium after infarction.

One potential application of self-healing hydrogels is the coating of medical implants. Biocompatible hydrogel coatings with good structural stability can be used to protect orthopedic implants or implanted sensors from biofouling $[21,177,178]$ or to deposit growth factors, cells or peptides on the implant surface $[178,179]$. The limitation in many bio-applications is the gel strength, which can be enhanced by secondary crosslinking or mixing with other polymers. The latter approach has been used in the preparation of an enteric elastomer (EE, Figure 16) from a mixture of H-bonding PA6ACA polymer, which is structurally similar to traditional enteric polymers, and poly(methacrylic acid-co-ethyl acrylate) (EUDRAGIT L 100-55) [180]. The stiffness of the resulting elastomer could be 
tuned by the ratio of these two polymers and the strongest gel reached the tensile strength of $\sim 3.3 \mathrm{MPa}$ and $>900 \%$ elongation at break. The elastomer was used to construct a gastric-retentive device with alternating pieces of harder polycaprolactone (PCL) linked together by EE gels. In vivo evaluation of the gastric device demonstrated that the device was intact in the acidic conditions of stomach, but dissociated into smaller pieces upon passing to small and large intestine with neutral $\mathrm{pH}$, where H-bonds start breaking upon the deprotonation of acid groups [180]. Hence, these supramolecular materials and their elastomers have strong potential in new gastric-resistant devices for weight control, ingestible electronics, and prolonged drug delivery. Recently, Gong and coworkers demonstrated the reprocessability of tough polyelectrolyte complex-based self-healing hydrogels into capsules, films, and fibers at ambient temperature [181].

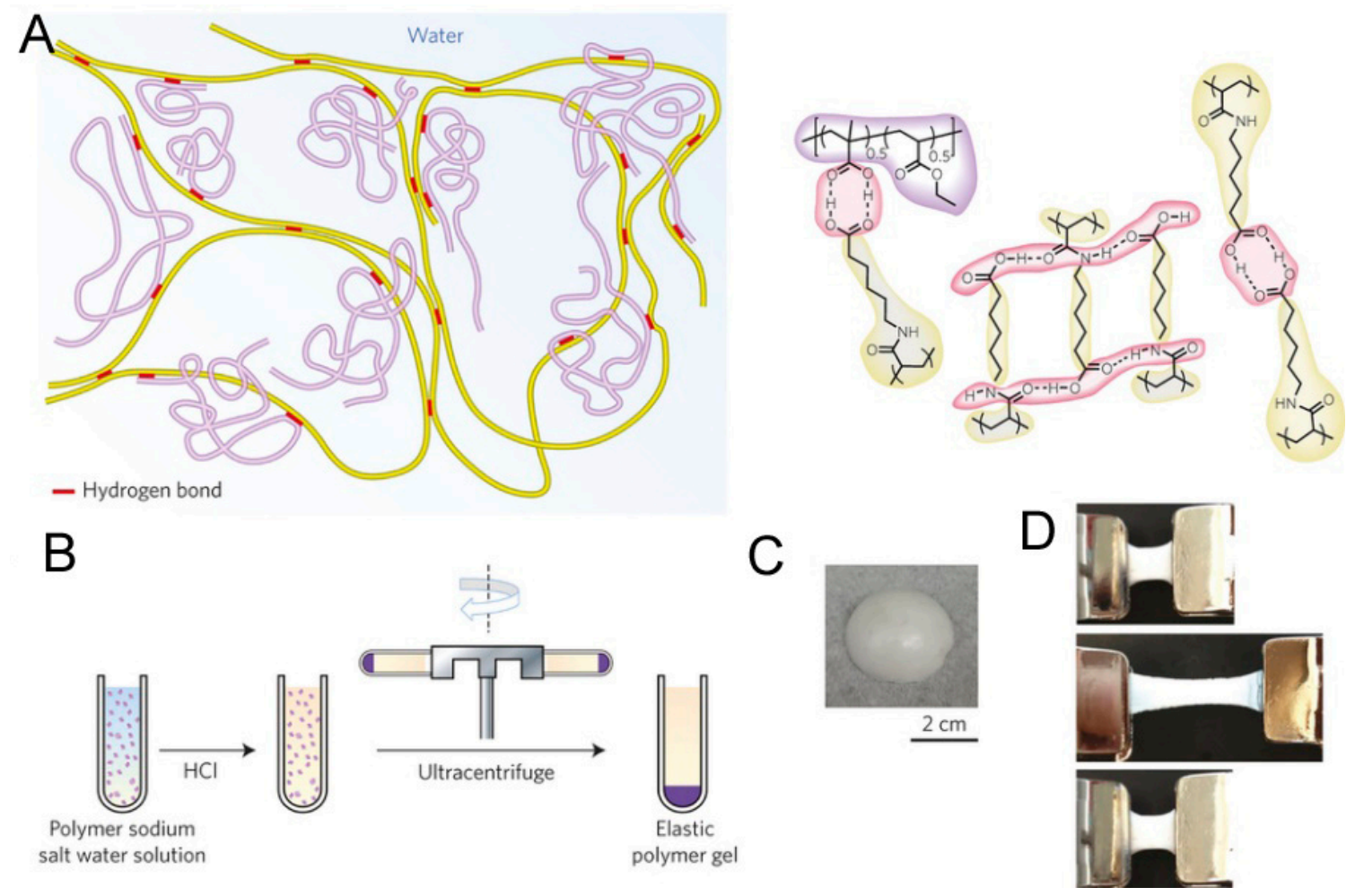

Figure 16. (A) Proposed supramolecular polymer gel network. Structures in yellow, synthesized poly(acryloyl 6-aminocaproic acid) (PA6ACA); structures in purple, linear poly(methacrylic acid-co-ethyl acrylate) (EUDRAGIT L 100-55); red part, inter-polymer hydrogen bonds; (B) Manufacturing process of the polymer gel. (Left), the homogeneous solution of PA6ACA sodium salt solution and L 100-55 sodium salt solution with varying polymer weight ratios. (Middle), the addition of $\mathrm{HCl}$ solution resulting in precipitation; (Right), formation of the elastic polymer gel after ultracentrifugation; (C) Photo of a piece of the polymer gel obtained after ultracentrifugation; and (D) Images of stretch and recovery testing of a polymer gel with PA6ACA:L 100-55=1:2. (Top), $1.5 \mathrm{~cm}$ piece of polymer gel held between two clamps. (Middle), stretching of the polymer gel to three times its initial length; (Bottom), recovery of the polymer gel $5 \mathrm{~min}$ after the external force was removed. Scale bar is $2 \mathrm{~cm}$ for (C) and (D). Reprinted with permission from [180]. Copyright 2016 Nature Publishing Group.

\section{Future Prospects and Conclusions}

Self-healing of hydrogels is relatively easier to achieve than in harder materials due to the higher mobility of the chains and the dynamic bonding interactions of the functional groups. Although supramolecular materials have been under extensive research for decades, the focus has only recently shifted on investigating how the reversibility of their physical interactions can be exploited at 
macroscopic scale for instance, in medical devices or delivery systems. The rapid structure recovery physical gels arising from the diffusion of polymer chains and interacting sites to the damaged area is beneficial in injection- and extrusion-based applications, but achieving a balance between the mechanical properties and recovery rate is challenging. The experimental data of mechanical strength and recovery of the various hydrogels reported are rather scattered and it is difficult to compare them directly due to the differences in experimental conditions and characterization methods used. It is thus difficult to indicate a clear trend that would guide in the selection of the most suitable preparation strategies. Often the choice of the preparation methods depends on the final use of the hydrogels in addition to the required physical properties. Among the physical interactions, hydrogen bonding seems to provide hydrogels of higher strengths with tensile and compression strengths of several MPa. Various techniques to reinforce the hydrogels are highlighted in this review and the most efficient ones combine several crosslinking mechanisms or involve mixing the supramolecularly crosslinking polymer with nano-fibers, -sheets or -particles, or blending with other polymers for better processability and enhanced lifetime.

These approaches show the highest potential for the use of self-healing hydrogels in therapeutic systems and medical devices and are expected to gain significant research interest in the future. Also, incorporating biologically active compounds, such as bile acids or peptides, as supramolecular building blocks is of increasing interest. The presence of pharmacologically active agents or cells may alter the crosslinking and degradation mechanisms of hydrogels, leading to changes in gel deformation and structure recovery and therefore, the long-term stability of each new hydrogel system would need to be investigated under physiological or cell culture conditions for biomedical applications. Physical hydrogels often exhibit time-dependent deformation, referred to as "creep", which is associated with high dissipative loss modulus in relation to elastic modulus and may affect the stem cell fate choice and tissue development in cell-seeded hydrogels [182]. In addition, the supramolecular carrier system should not interfere with the biological activity of the therapeutic agent. Self-healing physical gels provide a promising platform for building dynamic devices and systems, especially upon the recent innovations in 3D printing, and combining supramolecular and biotechnological approaches shows a great promise for the development of structurally controlled materials with tailored mechanical properties.

Acknowledgments: Financial support for research from NSERC of Canada and FRQNT of Quebec is gratefully acknowledged.

Author Contributions: Satu Strandman gathered the literature material, wrote the review and assembled the figure panels. X. X. Zhu organized the topics, contributed to the discussion of the contents and corrected the manuscript.

Conflicts of Interest: The authors declare no conflict of interest.

\section{Abbreviations}

The following abbreviations are used in this manuscript:

Ad

AdCANa

AAm

AAZ

Alg

ASAP

$\mathrm{CB}[\mathrm{n}]$

CBMAA-3

CD

Chol adamantane

sodium adamantanecarboxylate

acrylamide

carboxybetaine acrylate

alginate

sodium polyacrylate

cucurbit[n]uril, $n=$ number of glycouril units

(3-methacryloylaminopropyl)-(2-carboxyethyl)dimethylammonium-(carboxybetaine methacrylamide)

cyclodextrin

cholesterol 


$\begin{array}{ll}\text { CNS } & \text { clay nanosheets } \\ \text { DMAEMA } & \text { 2-(dimethylamino)ethyl methacrylate } \\ \text { DMAPS } & \text { 3-dimethyl(methacryloyloxyethyl) ammonium propane sulfonate } \\ \text { CTAB } & \text { cetyl trimethyl ammonium bromide } \\ \text { DMA } & \text { N,N'-dimethylacrylamide } \\ \text { DODAB } & \text { dimethyldioctadecylammonium bromide } \\ \text { EE } & \text { enteric elastomer } \\ \text { EPC } & \text { endothelial progenitor cell } \\ \text { FC } & \text { ferrocene } \\ \text { G' } & \text { storage modulus } \\ \text { G' } & \text { loss modulus } \\ \text { GO } & \text { graphene oxide } \\ \text { HA } & \text { hyaluronic acid } \\ \text { HEC } & \text { hydroxyethyl cellulose } \\ \text { HEMA } & \text { 2-hydroxyethyl methacrylate } \\ \text { MEO2MA } & \text { 2-(2-methoxyethoxy)ethyl methacrylate } \\ \text { MSC } & \text { mesenchymal stem cell } \\ \text { MV } & \text { methylviologen } \\ \text { NFC } & \text { nanofibrillar cellulose } \\ \text { NIPAAm } & \text { N-isopropylacrylamide } \\ \text { Np } & \text { naphthyl } \\ \text { PA6ACA } & \text { poly(6-acryloyl-6-aminocaproic acid) } \\ \text { PAAc } & \text { poly(acrylic acid) } \\ \text { PEG } & \text { poly(ethylene glycol) } \\ \text { PLGA } & \text { poly(L-glutamic acid) } \\ \text { PPG } & \text { poly(propylene glycol) } \\ \text { PVA } & \text { poly(vinyl alcohol) } \\ \text { RGD } & \text { arginine-glycine-aspartic acid } \\ \text { SCMHBMA } & \text { 2-(3-(6-methyl-4-oxo-1,4-dihydropyrimidin-2-yl)ureido)ethyl methacrylate } \\ \text { SDS } & \text { sodium dodecyl sulfate } \\ \text { SEM } & \text { scanning electron microscopy } \\ \text { STMV } & \text { methyl viologen-functionalized cationic polystyrene } \\ \text { UPy } & \text { 2-ureido-4[1H]pyrimidinone } \\ & \end{array}$

\section{References}

1. Almdal, K.; Dyre, J.; Hvidt, S.; Kramer, O. Towards a phenomenological definition of the term "Gel". Polym. Gels Netw. 1993, 1, 5-17. [CrossRef]

2. Flory, P.J. Introductory lecture. Faraday Discuss. Chem. Soc. 1974, 57, 7-18. [CrossRef]

3. Raghavan, S.R.; Douglas, J.F. The conundrum of gel formation by molecular nanofibers, wormlike micelles, and filamentous proteins: Gelation without cross-links? Soft Matter 2012, 8, 8539-8546. [CrossRef]

4. Ito, K. Slide-ring materials using topological supramolecular architecture. Curr. Opin. Solid State Mater. Sci. 2010, 14, 28-34. [CrossRef]

5. Peppas, N.A.; Hilt, J.Z.; Khademhosseini, A.; Langer, R. Hydrogels in biology and medicine: From molecular principles to bionanotechnology. Adv. Mater. 2006, 18, 1345-1360. [CrossRef]

6. Billiet, T.; Vandenhaute, M.; Schelfhout, J.; Van Vlierberghe, S.; Dubruel, P. A review of trends and limitations in hydrogel-rapid prototyping for tissue engineering. Biomaterials 2012, 33, 6020-6041. [CrossRef] [PubMed]

7. Hoffmann, A.S. Hydrogels for biomedical applications. Adv. Drug Deliv. Rev. 2012, 64, 18-23. [CrossRef] 
8. Nguyen, Q.V.; Huynh, D.P.; Park, J.H.; Lee, D.S. Injectable polymeric hydrogels for the delivery of therapeutic agents: A review. Eur. Polym. J. 2015, 72, 602-619. [CrossRef]

9. Calo, E.; Khutoryanskiy, V.V. Biomedical applications of hydrogels: A review of patents and commercial products. Eur. Polym. J. 2015, 65, 252-267. [CrossRef]

10. Buwalda, S.J.; Boere, K.W.M.; Dijkstra, P.J.; Feijen, J.; Vermonden, T.; Hennink, W.E. Hydrogels in a historical perspective: From simple networks to smart materials. J. Control. Release 2014, 190, 254-273. [CrossRef] [PubMed]

11. Kopecek, J. Hydrogels: From soft contact lenses and implants to self-assembled nanomaterials. J. Polym. Sci. A Polym. Chem. 2009, 47, 5929-5946. [CrossRef] [PubMed]

12. Bartnikowski, M.; Wellard, R.M.; Woodruff, M.; Klein, T. Tailoring hydrogel viscoelasticity with physical and chemical crosslinking. Polymers 2015, 7, 2650-2669. [CrossRef]

13. Lim, H.L.; Hwang, Y.; Kar, M.; Varghese, S. Smart hydrogels as functional biomimetic systems. Biomater. Sci. 2014, 2, 603-618. [CrossRef]

14. Richter, A.; Paschew, G.; Klatt, S.; Lienig, J.; Arndt, K.F.; Adler, H.J.P. Review on Hydrogel-based pH sensors and microsensors. Sensors 2008, 8, 561-581. [CrossRef]

15. Deligkaris, K.; Tadele, T.S.; Olthuis, W.; van den Berg, A. Hydrogel-based devices for biomedical applications. Sens. Actuator B Chem. 2010, 147, 765-774. [CrossRef]

16. Mateescu, A.; Wang, Y.; Dostalek, J.; Jonas, U. Thin hydrogel films for optical biosensor applications. Membranes 2012, 2, 40-69. [CrossRef] [PubMed]

17. Yetisen, A.K.; Butt, H.; Volpatti, L.R.; Pavlichenko, I.; Humar, M.; Kwok, S.J.J.; Koo, H.; Kim, K.S.; Naydenova, I.; Khademhosseini, A.; et al. Photonic hydrogel sensors. Biotechnol. Adv. 2015. [CrossRef] [PubMed]

18. Ionov, L. Hydrogel-based actuators: Possibilities and limitations. Mater. Today 2014, 17, 494-503. [CrossRef]

19. Carpi, F.; Smela, E. Biomedical Applications of Electroactive Polymer Actuators; John Wiley \& Sons: Chichester, UK, 2009; pp. 5-100.

20. Morais, J.; Papadimitrakopoulos, F.; Burgess, D. Biomaterials/Tissue interactions: Possible solutions to overcome foreign body response. AAPS J. 2010, 12, 188-196. [CrossRef] [PubMed]

21. Campoccia, D.; Montanaro, L.; Arciola, C.R. A review of the biomaterials technologies for infection-resistant surfaces. Biomaterials 2013, 34, 8533-8554. [CrossRef] [PubMed]

22. Cavallaro, A.; Taheri, S.; Vasilev, K. Responsive and "smart" antibacterial surfaces: Common approaches and new developments. Biointerphases 2014, 9, 029005. [CrossRef] [PubMed]

23. Boateng, J.S.; Matthews, K.H.; Stevens, H.N.E.; Eccleston, G.M. Wound healing dressings and drug delivery systems: A review. J. Pharm. Sci. 2008, 97, 2892-2923. [CrossRef] [PubMed]

24. Madaghiele, M.; Demitri, C.; Sannino, A.; Ambrosio, L. Polymeric hydrogels for burn wound care: Advanced skin wound dressings and regenerative templates. Burns Trauma 2014, 2, 153-161. [CrossRef]

25. Ghobril, C.; Grinstaff, M.W. The chemistry and engineering of polymeric hydrogel adhesives for wound closure: A tutorial. Chem. Soc. Rev. 2015, 44, 1820-1835. [CrossRef] [PubMed]

26. Kabiri, K.; Omidian, H.; Zohuriaan-Mehr, M.J.; Doroudiani, S. Superabsorbent hydrogel composites and nanocomposites: A review. Polym. Comp. 2011, 32, 277-289. [CrossRef]

27. Wan, J. Microfluidic-based synthesis of hydrogel particles for cell microencapsulation and cell-based drug delivery. Polymers 2012, 4, 1084-1108. [CrossRef]

28. Olabisi, R.M. Cell microencapsulation with synthetic polymers. J. Biomed. Mater. Res. A 2015, 103, 846-859. [CrossRef] [PubMed]

29. Wang, C.; Varshney, R.; Wang, D.A. Therapeutic cell delivery and fate control in hydrogels and hydrogel hybrids. Adv. Drug Deliv. Rev. 2010, 62, 699-710. [CrossRef] [PubMed]

30. Kearney, C.J.; Mooney, D.J. Macroscale delivery systems for molecular and cellular payloads. Nat. Mater. 2013, 12, 1004-1017. [CrossRef] [PubMed]

31. Nicolson, P.C.; Vogt, J. Soft contact lens polymers: An evolution. Biomaterials 2001, 22, 3273-3283. [CrossRef]

32. Rubinstein, M.P. Applications of contact lens devices in the management of corneal disease. Eye 2003, 17, 872-876. [CrossRef] [PubMed]

33. Xinming, L.; Yingde, C.; Lloyd, A.W.; Mikhalovsky, S.V.; Sandeman, S.R.; Howel, C.A.; Liewen, L. Polymeric hydrogels for novel contact lens-based ophthalmic drug delivery systems: A review. Contact Lens Anterior Eye 2008, 31, 57-64. [CrossRef] [PubMed] 
34. Kharkar, P.M.; Kiick, K.L.; Kloxin, A.M. Designing degradable hydrogels for orthogonal control of cell microenvironments. Chem. Soc. Rev. 2013, 42, 7335-7372. [CrossRef] [PubMed]

35. Gibbs, D.M.R.; Black, C.R.M.; Dawson, J.I.; Oreffo, R.O.C. A review of hydrogel use in fracture healing and bone regeneration. J. Tissue Eng. Regen. Med. 2014. [CrossRef] [PubMed]

36. Hastings, C.L.; Roche, E.T.; Ruiz-Hernandez, E.; Schenke-Layland, K.; Walsh, C.J.; Duffy, G.P. Drug and cell delivery for cardiac regeneration. Adv. Drug Deliv. Rev. 2015, 84, 85-106. [CrossRef] [PubMed]

37. Muehleder, S.; Ovsianikov, A.; Zipperle, J.; Redl, H.; Holnthoner, W. Connections matter: Channeled hydrogels to improve vascularization. Front. Bioeng. Biotechnol. 2014, 2, 1-7.

38. Ligoure, C.; Mora, S. Fractures in complex fluids: The case of transient networks. Rheol. Acta 2013, 52, 91-114. [CrossRef]

39. Garcia, S.J. Effect of polymer architecture on the intrinsic self-healing character of polymers. Eur. Polym. J. 2014, 53, 118-125. [CrossRef]

40. Wei, Z.; Yang, J.H.; Zhou, J.; Xu, F.; Zrinyi, M.; Dussault, P.H.; Osada, Y.; Chen, Y.M. Self-healing gels based on constitutional dynamic chemistry and their potential applications. Chem. Soc. Rev. 2014, 43, 8114-8131. [CrossRef] [PubMed]

41. Yang, Y.; Ding, X.; Urban, M.W. Chemical and physical aspects of self-healing materials. Prog. Polym. Sci. 2015, 49-50, 34-59. [CrossRef]

42. Yang, X.; Yu, H.; Wang, L.; Tong, R.; Akram, M.; Chen, Y.; Zhai, X. Self-healing polymer materials constructed by macrocycle-based host-guest interactions. Soft Matter 2015, 11, 1242-1252. [CrossRef] [PubMed]

43. Herbst, F.; Döhler, D.; Michael, P.; Binder, W.H. Self-healing polymers via supramolecular forces. Macromol. Rapid Commun. 2013, 34, 203-220. [CrossRef] [PubMed]

44. Dong, R.; Pang, Y.; Su, Y.; Zhu, X. Supramolecular hydrogels: Synthesis, properties and their biomedical applications. Biomater. Sci. 2015, 3, 937-954. [CrossRef] [PubMed]

45. An, S.Y.; Arunbabu, D.; Noh, S.M.; Song, Y.K.; Oh, J.K. Recent strategies to develop self-healable crosslinked polymeric networks. Chem. Commun. 2015, 51, 13058-13070. [CrossRef] [PubMed]

46. Sanyal, A. Diels-Alder cycloaddition-cycloreversion: A powerful combo in materials design. Macromol. Chem. Phys. 2010, 211, 1417-1425. [CrossRef]

47. Gandini, A. The furan/maleimide Diels-Alder reaction: A versatile click-unclick tool in macromolecular synthesis. Prog. Polym. Sci. 2013, 38, 1-29. [CrossRef]

48. Liu, Y.L.; Chuo, T.W. Self-healing polymers based on thermally reversible Diels-Alder chemistry. Polym. Chem. 2013, 4, 2194-2205. [CrossRef]

49. Wei, Z.; Yang, J.H.; Du, X.J.; Xu, F.; Zrinyi, M.; Osada, Y.; Li, F.; Chen, Y.M. Dextran-based self-healing hydrogels formed by reversible Diels-Alder reaction under physiological conditions. Macromol. Rapid Commun. 2013, 34, 1464-1470. [CrossRef] [PubMed]

50. Yu, F.; Cao, X.; Du, J.; Wang, G.; Chen, X. Multifunctional hydrogel with good structure integrity, self-healing, and tissue-adhesive property formed by combining Diels-Alder click reaction and acylhydrazone bond. ACS Appl. Mater. Interfaces 2015, 7, 24023-24031. [CrossRef] [PubMed]

51. Gyarmati, B.; Némethy, Á.; Szilágyi, A. Reversible disulphide formation in polymer networks: A versatile functional group from synthesis to applications. Eur. Polym. J. 2013, 49, 1268-1286. [CrossRef]

52. Deng, G.; Li, F.; Yu, H.; Liu, F.; Liu, C.; Sun, W.; Jiang, H.; Chen, Y. Dynamic hydrogels with an environmental adaptive self-healing ability and dual responsive sol-gel transitions. ACS Macro Lett. 2012, 1, 275-279. [CrossRef]

53. Casuso, P.; Odriozola, I.; Pérez-San Vicente, A.; Loinaz, I.; Cabañero, G.; Grande, H.J.; Dupin, D. Injectable and self-healing dynamic hydrogels based on metal(I)-thiolate/disulfide exchange as biomaterials with tunable mechanical properties. Biomacromolecules 2015, 16, 3552-3561. [CrossRef] [PubMed]

54. Haldar, U.; Bauri, K.; Li, R.; Faust, R.; De, P. Polyisobutylene-based pH-responsive self-healing polymeric gels. ACS Appl. Mater. Interfaces 2015, 7, 8779-8788. [CrossRef] [PubMed]

55. Zhang, Y.; Tao, L.; Li, S.; Wei, Y. Synthesis of multiresponsive and dynamic chitosan-based hydrogels for controlled release of bioactive molecules. Biomacromolecules 2011, 12, 2894-2901. [CrossRef] [PubMed]

56. Mukherjee, S.; Hill, M.R.; Sumerlin, B.S. Self-healing hydrogels containing reversible oxime crosslinks. Soft Matter 2015, 11, 6152-6161. [CrossRef] [PubMed]

57. Fiore, G.L.; Rowan, S.J.; Weder, C. Optically healable polymers. Chem. Soc. Rev. 2013, 42, 7278-7288. [CrossRef] [PubMed] 
58. Amamoto, Y.; Kamada, J.; Otsuka, H.; Takahara, A.; Matyjaszewski, K. Repeatable photoinduced self-healing of covalently cross-linked polymers through reshuffling of trithiocarbonate units. Angew. Chem. 2011, 123, 1698-1701. [CrossRef]

59. Imato, K.; Nishihara, M.; Kanehara, T.; Amamoto, Y.; Takahara, A.; Otsuka, H. Self-healing of chemical gels cross-linked by diarylbibenzofuranone-based trigger-free dynamic covalent bonds at room temperature. Angew. Chem. Int. Ed. 2012, 51, 1138-1142. [CrossRef] [PubMed]

60. Roberts, M.C.; Hanson, M.C.; Massey, A.P.; Karren, E.A.; Kiser, P.F. Dynamically restructuring hydrogel networks formed with reversible covalent crosslinks. Adv. Mater. 2007, 19, 2503-2507. [CrossRef]

61. He, L.; Fullenkamp, D.E.; Rivera, J.G.; Messersmith, P.B. pH responsive self-healing hydrogels formed by boronate-catechol complexation. Chem. Commun. 2011, 47, 7497-7499. [CrossRef] [PubMed]

62. Deng, C.C.; Brooks, W.L.A.; Abboud, K.A.; Sumerlin, B.S. Boronic acid-based hydrogels undergo self-healing at neutral and acidic pH. ACS Macro Lett. 2015, 4, 220-224. [CrossRef]

63. Jia, Y.-G.; Zhu, X.X. Self-healing supramolecular hydrogel made of polymers bearing cholic acid and $\beta$-cyclodextrin pendants. Chem. Mater. 2015, 27, 387-393. [CrossRef]

64. Hillewaere, X.K.D.; Du Prez, F.E. Fifteen chemistries for autonomous external self-healing polymers and composites. Prog. Polym. Sci. 2015, 49-50, 121-153. [CrossRef]

65. Roy, N.; Bruchmann, B.; Lehn, J.-M. DYNAMERS: Dynamic polymers as self-healing materials. Chem. Soc. Rev. 2015, 44, 3786-3807. [CrossRef] [PubMed]

66. Zhang, Y.; Barboiu, M. Constitutional dynamic materials-Toward natural selection of function. Chem. Rev. 2015. [CrossRef] [PubMed]

67. Krogsgaard, M.; Nue, V.; Birkedal, H. Mussel-inspired materials: Self-healing through coordination chemistry. Chem. Eur. J. 2016, 22, 844-857. [CrossRef] [PubMed]

68. Wang, H.; Heilshorn, S.C. Adaptable hydrogel networks with reversible linkages for tissue engineering. Adv. Mater. 2015, 27, 3717-3736. [CrossRef] [PubMed]

69. Stukalin, E.B.; Cai, L.-H.; Kumar, N.A.; Leibler, L.; Rubinstein, M. Self-healing of unentangled polymer networks with reversible bonds. Macromolecules 2013, 46, 7525-7541. [CrossRef] [PubMed]

70. Ahmadi, M.; Hawke, L.G.D.; Goldansaz, H.; van Ruymbeke, E. Dynamics of entangled linear supramolecular chains with sticky side groups: Influence of hindered fluctuations. Macromolecules 2015, 48, 7300-7310. [CrossRef]

71. Hackelbusch, S.; Rossow, T.; van Assenbergh, P.; Seiffert, S. Chain dynamics in supramolecular polymer networks. Macromolecules 2013, 46, 6273-6286. [CrossRef]

72. Tuncaboylu, D.C.; Argun, A.; Algi, M.P.; Okay, O. Autonomic self-healing in covalently crosslinked hydrogels containing hydrophobic domains. Polymer 2013, 54, 6381-6388. [CrossRef]

73. Zhang, H.; Xia, H.; Zhao, Y. Poly(vinyl alcohol) hydrogel can autonomously self-heal. ACS Macro Lett. 2012, 1, 1233-1236. [CrossRef]

74. Cui, W.; Ji, J.; Cai, Y.-F.; Li, H.; Ran, R. Robust, anti-fatigue, and self-healing graphene oxide/hydrophobically associated composite hydrogels and their use as recyclable adsorbents for dye wastewater treatment. J. Mater. Chem. A 2015, 3, 17445-17458. [CrossRef]

75. Berne, B.J.; Weeks, J.D.; Zhou, R. Dewetting and hydrophobic interaction in physical and biological systems. Ann. Rev. Phys. Chem. 2009, 60, 85-103. [CrossRef]

76. Otto, S.; Engberts, J.B.F.N. Hydrophobic interactions and chemical reactivity. Org. Biomol. Chem. 2003, 1, 2809-2820. [CrossRef] [PubMed]

77. Winnik, M.A.; Yekta, A. Associative polymers in aqueous solution. Curr. Opin. Colloid Interface Sci. 1997, 2, 424-436. [CrossRef]

78. Chassenieux, C.; Nicolai, T.; Benyahia, L. Rheology of associative polymer solutions. Curr. Opin. Colloid Interface Sci. 2011, 16, 18-26. [CrossRef]

79. Hietala, S.; Strandman, S.; Järvi, P.; Torkkeli, M.; Jankova, K.; Hvilsted, S.; Tenhu, H. Rheological properties of associative star polymers in aqueous solutions: Effect of hydrophobe length and polymer topology. Macromolecules 2009, 42, 1726-1732. [CrossRef]

80. Gulyuz, U.; Okay, O. Self-healing poly(acrylic acid) hydrogels with shape memory behavior of high mechanical strength. Macromolecules 2014, 47, 6889-6899. [CrossRef]

81. Tuncaboylu, D.C.; Sari, M.; Oppermann, W.; Okay, O. Tough and Self-Healing Hydrogels Formed via Hydrophobic Interactions. Macromolecules 2011, 44, 4997-5005. [CrossRef] 
82. Akay, G.; Hassan-Raeisi, A.; Tuncaboylu, D.C.; Orakdogen, N.; Abdurrahmanoglu, S.; Oppermann, W.; Okay, O. Self-healing hydrogels formed in catanionic surfactant solutions. Soft Matter 2013, 9, 2254-2261. [CrossRef]

83. Algi, M.P.; Okay, O. Highly stretchable self-healing poly $(N, N$-dimethylacrylamide $)$ hydrogels. Eur. Polym. J. 2014, 59, 113-121. [CrossRef]

84. Gulyuz, U.; Okay, O. Self-healing poly(N-isopropylacrylamide) hydrogels. Eur. Polym. J. 2015, 72, 12-22. [CrossRef]

85. Jiang, G.; Liu, C.; Liu, X.; Zhang, G.; Yang, M.; Chen, Q.; Liu, F. Self-healing Mechanism and Mechanical Behavior of Hydrophobic Association Hydrogels with High Mechanical Strength. J. Macromol. Sci. A 2010, 47, 335-342. [CrossRef]

86. Chang, H.-I.; Yeh, M.-K. Clinical development of liposome-based drugs: Formulation, characterization, and therapeutic efficacy. Int. J. Nanomed. 2012, 7, 49-60.

87. Rao, Z.; Inoue, M.; Matsuda, M.; Taguchi, T. Quick self-healing and thermo-reversible liposome gel. Colloids Surf. B Biointerfaces 2011, 82, 196-202. [CrossRef] [PubMed]

88. Wei, P.; Yan, X.; Huang, F. Supramolecular polymers constructed by orthogonal self-assembly based on host-guest and metal-ligand interactions. Chem. Soc. Rev. 2015, 44, 815-832. [CrossRef] [PubMed]

89. Harada, A.; Takashima, Y.; Nakahata, M. Supramolecular Polymeric Materials via Cyclodextrin-Guest Interactions. Acc. Chem. Res. 2014, 47, 2128-2140. [CrossRef] [PubMed]

90. Schneider, H.-J.; Yatsimirsky, A.K. Selectivity in supramolecular host-guest complexes. Chem. Soc. Rev. 2008, 37, 263-277. [CrossRef] [PubMed]

91. Schmidtchen, F.P. Reflections on the construction of anion receptors: Is there a sign to resign from design? Coord. Chem. Rev. 2006, 250, 2918-2928. [CrossRef]

92. Gokel, G.W.; Leevy, W.M.; Weber, M.E. Crown Ethers: Sensors for Ions and Molecular Scaffolds for Materials and Biological Models. Chem. Rev. 2004, 104, 2723-2750. [CrossRef] [PubMed]

93. Späth, A.; König, B. Molecular recognition of organic ammonium ions in solution using synthetic receptors. Beilstein J. Org. Chem. 2010, 32, 1-111. [CrossRef] [PubMed]

94. Zeng, F.; Han, Y.; Yan, Z.-C.; Liu, C.-Y.; Chen, C.-F. Supramolecular polymer gel with multi stimuli responsive, self-healing and erasable properties generated by host-guest interactions. Polymer 2013, 54, 6929-6935. [CrossRef]

95. Zhang, M.; Xu, D.; Yan, X.; Chen, J.; Dong, S.; Zheng, B.; Huang, F. Self-Healing Supramolecular Gels Formed by Crown Ether Based-Guest Interactions. Angew. Chem. 2012, 124, 7117-7121. [CrossRef]

96. Folch-Cano, C.; Yazdani-Pedram, M.; Claudio Olea-Azar, C. Inclusion and Functionalization of Polymers with Cyclodextrins: Current Applications and Future Prospects. Molecules 2014, 19, 14066-14079. [CrossRef] [PubMed]

97. Tan, S.; Ladewig, K.; Fu, Q.; Blencowe, A.; Qiao, G.G. Cyclodextrin-Based Supramolecular Assemblies and Hydrogels: Recent Advances and Future Perspectives. Macromol. Rapid Commun. 2014, 35, 1166-1184. [CrossRef] [PubMed]

98. Harada, A.; Hashidzume, A.; Yamaguchi, H.; Takashima, Y. Polymeric Rotaxanes. Chem. Rev. 2009, 109, 5974-6023. [CrossRef] [PubMed]

99. Nakahata, M.; Takashima, Y.; Yamaguchi, H.; Harada, A. Redox-responsive self-healing materials formed from host-guest polymers. Nat. Commun. 2011, 2, 511-516. [CrossRef] [PubMed]

100. Yan, Q.; Feng, A.; Zhang, H.; Yin, Y.; Yuan, J. Redox-switchable supramolecular polymers for responsive self-healing nanofibers in water. Polym. Chem. 2013, 4, 1216-1220. [CrossRef]

101. Wang, Y.-F.; Zhang, D.-L.; Zhou, T.; Zhang, H.-S.; Zhang, W.-Z.; Luo, L.; Zhang, A.-M.; Li, B.-J.; Zhang, S. A reversible functional supramolecular material formed by host-guest inclusion. Polym. Chem. 2014, 5, 2922-2927. [CrossRef]

102. Chuo, T.-W.; Wei, T.-C.; Liu, Y.-L. Electrically driven self-healing polymers based on reversible guest-host complexation of $\beta$-cyclodextrin and ferrocene. J. Polym. Sci. A Polym. Chem. 2013, 51, 3395-3403. [CrossRef]

103. Yu, C.; Wang, C.-F.; Chen, S. Robust Self-Healing Host-Guest Gels from Magnetocaloric Radical Polymerization. Adv. Funct. Mater. 2014, 24, 1235-1242. [CrossRef]

104. Chen, H.; Ma, X.; Wu, S.; Tian, H. A Rapidly Self-Healing Supramolecular Polymer Hydrogel with Photostimulated Room-Temperature Phosphorescence Responsiveness. Angew. Chem. Int. Ed. 2014, 53, 14149-14152. [CrossRef] [PubMed] 
105. Zhang, Y.H.; Zhu, X.X. Polymers made from cholic acid derivatives: Selected properties. Macromol. Chem. Phys. 1996, 197, 3473-3482. [CrossRef]

106. Le Dévédec, F.; Fuentealba, D.; Strandman, S.; Bohne, C.; Zhu, X.X. Aggregation Behavior of Pegylated Bile Acid Derivatives. Langmuir 2012, 28, 13431-13440. [CrossRef] [PubMed]

107. Shao, Y.; Jia, Y.-G.; Shi, C.; Luo, J.; Zhu, X.X. Block and Random Copolymers Bearing Cholic Acid and Oligo(ethylene glycol) Pendant Groups: Aggregation, Thermosensitivity, and Drug Loading. Biomacromolecules 2014, 15, 1837-1844. [CrossRef] [PubMed]

108. Strandman, S.; Zhu, X.X. Biodegradable Shape Memory Polymers for Biomedical Applications. In Shape Memory Polymers for Biomedical Applications; Yahia, L.H., Ed.; Woodhead Publishing: Cambridge, UK, 2015; Volume Chapter 11, pp. 219-245.

109. Jia, Y.-G.; Zhu, X.X. Thermoresponsiveness of Copolymers Bearing Cholic Acid Pendants Induced by Complexation with $\beta$-Cyclodextrin. Langmuir 2014, 30, 11770-11775. [CrossRef] [PubMed]

110. Li, G.; Wu, J.; Wang, B.; Yan, S.; Zhang, K.; Ding, J.; Yin, J. Self-Healing Supramolecular Self-Assembled Hydrogels Based on Poly(L-glutamic acid). Biomacromolecules 2015, 16, 3508-3518. [CrossRef] [PubMed]

111. Miao, T.; Fenn, S.L.; Charron, P.N.; Oldinski, R.A. Self-Healing and Thermoresponsive Dual-Cross-Linked Alginate Hydrogels Based on Supramolecular Inclusion Complexes. Biomacromolecules 2015, 16, 3740-3750. [CrossRef] [PubMed]

112. Nakahata, M.; Takashima, Y.; Harada, A. Highly Flexible, Tough, and Self-Healing Supramolecular Polymeric Materials Using Host-Guest Interaction. Macromol. Rapid Commun. 2016, 37, 86-92. [CrossRef] [PubMed]

113. Miyamae, K.; Nakahata, M.; Takashima, Y.; Harada, A. Self-Healing, Expansion-Contraction, and Shape-Memory Properties of a Preorganized Supramolecular Hydrogel through Host-Guest Interactions. Angew. Chem. 2015, 127, 9112-9115. [CrossRef]

114. Kakuta, T.; Takashima, Y.; Nakahata, M.; Otsubo, M.; Yamaguchi, H.; Harada, A. Preorganized Hydrogel: Self-Healing Properties of Supramolecular Hydrogels Formed by Polymerization of Host-Guest-Monomers that Contain Cyclodextrins and Hydrophobic Guest Groups. Adv. Mater. 2013, 25, 2849-2853. [CrossRef] [PubMed]

115. Barrow, S.J.; Kasera, S.; Rowland, M.J.; del Barrio, J.; Scherman, O.A. Cucurbituril-Based Molecular Recognition. Chem. Rev. 2015, 115, 12320-12406. [CrossRef] [PubMed]

116. Rauwald, U.; Scherman, O.A. Supramolecular Block Copolymers with Cucurbit[8]uril in Water. Angew. Chem. Int. Ed. 2008, 47, 3950-3953. [CrossRef] [PubMed]

117. Rauwald, U.; Biedermann, F.; Deroo, S.; Robinson, C.V.; Scherman, O.A. Correlating Solution Binding and ESI-MS Stabilities by Incorporating Solvation Effects in a Confined Cucurbit[8]uril System. J. Phys. Chem. B 2010, 114, 8606-8615. [CrossRef] [PubMed]

118. Kim, K.; Selvapalam, N.; Ko, Y.H.; Park, K.M.; Kim, D.; Kim, J. Functionalized cucurbiturils and their applications. Chem. Soc. Rev. 2007, 36, 267-279. [CrossRef] [PubMed]

119. Assaf, K.I.; Nau, W.M. Cucurbiturils: From synthesis to high-affinity binding and catalysis. Chem. Soc. Rev. 2015, 44, 394-418. [CrossRef] [PubMed]

120. Appel, E.A.; Biedermann, F.; Rauwald, U.; Jones, S.T.; Zayed, J.M.; Scherman, O.A. Supramolecular Cross-Linked Networks via Host-Guest Complexation with Cucurbit[8]uril. J. Am. Chem. Soc. 2010, 132, 14251-14260. [CrossRef] [PubMed]

121. Appel, E.A.; Loh, X.J.; Jones, S.T.; Biedermann, F.; Dreiss, C.A.; Scherman, O.A. Ultrahigh-Water-Content Supramolecular Hydrogels Exhibiting Multistimuli Responsiveness. J. Am. Chem. Soc. 2012, 134, 11767-11773. [CrossRef] [PubMed]

122. Janeček, E.-R.; McKee, J.R.; Tan, C.S.Y.; Nykänen, A.; Kettunen, M.; Laine, J.; Ikkala, O.; Scherman, O.A. Hybrid Supramolecular and Colloidal Hydrogels that Bridge Multiple Length Scales. Angew. Chem. Int. Ed. 2015, 54, 5383-5388. [CrossRef] [PubMed]

123. Xiao, X.; Sun, N.; Qi, D.; Jiang, J. Unprecedented cucurbituril-based ternary host-guest supramolecular polymers mediated through included alkyl chains. Polym. Chem. 2014, 5, 5211-5217. [CrossRef]

124. Kulkarni, S.G.; Prucková, Z.; Rouchal, M.; Dastychová, L.; Vícha, R. Adamantylated trisimidazolium-based tritopic guests and their binding properties towards cucurbit[7]uril and $\beta$-cyclodextrin. J. Incl. Phenom. Macrocycl. Chem. 2015, 1-10. [CrossRef] 
125. Walsh, Z.; Janeček, E.-R.; Hodgkinson, J.T.; Sedlmair, J.; Koutsioubas, A.; Spring, D.R.; Welch, M.; Hirschmugl, C.J.; Toprakcioglu, C.; Nitschke, J.R.; et al. Multifunctional supramolecular polymer networks as next-generation consolidants for archaeological wood conservation. Proc. Natl. Acad. Sci. USA 2014, 111, 17743-17748. [CrossRef] [PubMed]

126. Brunsveld, L.; Folmer, B.J.B.; Meijer, E.W.; Sijbesma, R.P. Supramolecular Polymers. Chem. Rev. 2001, 101, 4071-4098. [CrossRef] [PubMed]

127. Chirila, T.V.; Lee, H.H.; Oddon, M.; Nieuwenhuizen, M.M.L.; Blakey, I.; Nicholson, T.M. Hydrogen-bonded supramolecular polymers as self-healing hydrogels: Effect of a bulky adamantyl substituent in the ureido-pyrimidinone monomer. J. Appl. Polym. Sci. 2014, 131, 39932. [CrossRef]

128. Van Gemert, G.M.L.; Peeters, J.W.; Söntjens, S.H.M.; Janssen, H.M.; Bosman, A.W. Self-Healing Supramolecular Polymers in Action. Macromol. Chem. Phys. 2012, 213, 234-242.

129. Dankers, P.Y.W.; Hermans, T.M.; Baughman, T.W.; Kamikawa, Y.; Kieltyka, R.E.; Bastings, M.M.C.; Janssen, H.M.; Sommerdijk, N.A.J.M.; Larsen, A.; van Luyn, M.J.A.; et al. Hierarchical Formation of Supramolecular Transient Networks in Water: A Modular Injectable Delivery System. Adv. Mater. 2012, 24, 2703-2709. [CrossRef] [PubMed]

130. Kieltyka, R.E.; Pape, A.C.H.; Albertazzi, L.; Nakano, Y.; Bastings, M.M.C.; Voets, I.K.; Dankers, P.Y.W.; Meijer, E.W. Mesoscale Modulation of Supramolecular Ureidopyrimidinone-Based Poly(ethylene glycol) Transient Networks in Water. J. Am. Chem. Soc. 2013, 135, 11159-11164. [CrossRef] [PubMed]

131. Weiss, R.G., Terech, P., Eds.; Molecular Gels. Materials with Self-Assembled Fibrillar Networks; Springer: Dordrecht, The Netherlands, 2006.

132. Weiss, R.G. The Past, Present, and Future of Molecular Gels. What Is the Status of the Field, and Where Is It Going? J. Am. Chem. Soc. 2014, 136, 7519-7530. [CrossRef] [PubMed]

133. Brizard, A.M.; Stuart, M.C.A.; van Esch, J.H. Self-assembled interpenetrating networks by orthogonal self assembly of surfactants and hydrogelators. Faraday Discuss. 2009, 143, 345-357. [CrossRef] [PubMed]

134. Strandman, S.; Le Dévédec, F.; Zhu, X.X. Self-Assembly of Bile Acid-PEG Conjugates in Aqueous Solutions. J. Phys. Chem. B 2013, 117, 252-258. [CrossRef] [PubMed]

135. Cui, J.; Campo, A.D. Multivalent H-bonds for self-healing hydrogels. Chem. Commun. 2012, 48, 9302-9304. [CrossRef] [PubMed]

136. Lin, Y.; Li, G. An intermolecular quadruple hydrogen-bonding strategy to fabricate self-healing and highly deformable polyurethane hydrogels. J. Mat. Chem. B 2014, 2, 6878-6885. [CrossRef]

137. Phadke, A.; Zhang, C.; Arman, B.; Hsu, C.-C.; Mashelkar, R.A.; Lele, A.K.; Tauber, M.J.; Arya, G.; Varghese, S. Rapid self-healing hydrogels. Proc. Natl. Acad. Sci. USA 2012, 109, 4383-4388. [CrossRef] [PubMed]

138. Varghese, S.; Lele, A.; Mashelkar, R. Metal-ion-mediated healing of gels. J. Polym. Sci. A Polym. Chem. 2006, 44, 666-670. [CrossRef]

139. Dai, X.; Zhang, Y.; Gao, L.; Bai, T.; Wang, W.; Cui, Y.; Liu, W. A Mechanically Strong, Highly Stable, Thermoplastic, and Self-Healable Supramolecular Polymer Hydrogel. Adv. Mater. 2015, 27, 3566-3571. [CrossRef] [PubMed]

140. Zhang, L.; Brostowitz, N.R.; Cavicchi, K.A.; Weiss, R.A. Perspective: Ionomer Research and Applications. Macromol. React. Eng. 2014, 8, 81-99. [CrossRef]

141. Lin, X.; Grinstaff, M.W. Ionic Supramolecular Assemblies. Israel J. Chem. 2013, 53, 498-510. [CrossRef]

142. Lin, X.; Navailles, L.; Nallet, F.; Grinstaff, M.W. Influence of Phosphonium Alkyl Substituents on the Rheological and Thermal Properties of Phosphonium-PAA-Based Supramolecular Polymeric Assemblies. Macromolecules 2012, 45, 9500-9506. [CrossRef]

143. Sun, J.-Y.; Zhao, X.; Illeperuma, W.R.K.; Chaudhuri, O.; Oh, K.H.; Mooney, D.J.; Vlassak, J.J.; Suo, Z. Highly stretchable and tough hydrogels. Nature 2012, 489, 133-136. [CrossRef] [PubMed]

144. Bai, T.; Liu, S.; Sun, F.; Sinclair, A.; Zhang, L.; Shao, Q.; Jiang, S. Zwitterionic fusion in hydrogels and spontaneous and time-independent self-healing under physiological conditions. Biomaterials 2014, 35, 3926-3933. [CrossRef] [PubMed]

145. Liu, H.; Xiong, C.; Tao, Z.; Fan, Y.; Tang, X.; Yang, H. Zwitterionic copolymer-based and hydrogen bonding-strengthened self-healing hydrogel. RSC Adv. 2015, 5, 33083-33088. [CrossRef]

146. Kostina, N.Y.; Sharifi, S.; de los Santos Pereira, A.; Michalek, J.; Grijpma, D.W.; Rodriguez-Emmenegger, C. Novel antifouling self-healing poly(carboxybetaine methacrylamide-co-HEMA) nanocomposite hydrogels with superior mechanical properties. J. Mater. Chem. B 2013, 1, 5644-5650. [CrossRef] 
147. Haraguchi, K.; Ning, J.; Li, G. Changes in the Properties and Self-Healing Behaviors of Zwitterionic Nanocomposite Gels across Their UCST Transition. Macromol. Symp. 2015, 358, 182-193. [CrossRef]

148. Wang, Q.; Mynar, J.L.; Yoshida, M.; Lee, E.; Lee, M.; Okuro, K.; Kinbara, K.; Aida, T. High-water-content mouldable hydrogels by mixing clay and a dendritic molecular binder. Nature 2010, 463, 339-343. [CrossRef] [PubMed]

149. Wei, H.; Du, S.; Liu, Y.; Zhao, H.; Chen, C.; Li, Z.; Lin, J.; Zhang, Y.; Zhang, J.; Wan, X. Tunable, luminescent, and self-healing hybrid hydrogels of polyoxometalates and triblock copolymers based on electrostatic assembly. Chem. Commun. 2014, 50, 1447-1450. [CrossRef] [PubMed]

150. Zhang, L.; Qian, J.; Fan, Y.; Feng, W.; Tao, Z.; Yang, H. A facile $\mathrm{CO}_{2}$ switchable nanocomposite with reversible transition from sol to self-healable hydrogel. RSC Adv. 2015, 5, 62229-62234. [CrossRef]

151. Haraguchi, K.; Uyama, K.; Tanimoto, H. Self-healing in Nanocomposite Hydrogels. Macromol. Rapid Commun. 2011, 32, 1253-1258. [CrossRef] [PubMed]

152. Han, D.; Yan, L. Supramolecular Hydrogel of Chitosan in the Presence of Graphene Oxide Nanosheets as 2D Cross-Linkers. ACS Sustain. Chem. Eng. 2014, 2, 296-300. [CrossRef]

153. Cong, H.-P.; Wang, P.; Yu, S.-H. Stretchable and Self-Healing Graphene Oxide-Polymer Composite Hydrogels: A Dual-Network Design. Chem. Mater. 2013, 25, 3357-3362. [CrossRef]

154. Guvendiren, M.; Lu, H.D.; Burdick, J.A. Shear-thinning hydrogels for biomedical applications. Soft Matter 2012, 8, 260-272. [CrossRef]

155. Desai, M.S.; Lee, S.-W. Protein-based functional nanomaterial design for bioengineering applications. WIREs Nanomed. Nanobiotechnol. 2015, 7, 69-97. [CrossRef] [PubMed]

156. Song, P.A.; Xu, Z.; Guo, Q. Bioinspired Strategy to Reinforce PVA with Improved Toughness and Thermal Properties via Hydrogen-Bond Self-Assembly. ACS Macro Lett. 2013, 2, 1100-1104. [CrossRef]

157. Li, G.; Yan, Q.; Xia, H.; Zhao, Y. Therapeutic-Ultrasound-Triggered Shape Memory of a Melamine-Enhanced Poly(vinyl alcohol) Physical Hydrogel. ACS Appl. Mater. Interfaces 2015, 7, 12067-12073. [CrossRef] [PubMed]

158. Li, G.; Zhang, H.; Fortin, D.; Xia, H.; Zhao, Y. Poly(vinyl alcohol)-Poly(ethylene glycol) Double-Network Hydrogel: A General Approach to Shape Memory and Self-Healing Functionalities. Langmuir 2015, 31, 11709-11716. [CrossRef] [PubMed]

159. Golinska, M.D.; Włodarczyk-Biegun, M.K.; Werten, M.W.T.; Stuart, M.A.C.; de Wolf, F.A.; de Vries, R. Dilute Self-Healing Hydrogels of Silk-Collagen-Like Block Copolypeptides at Neutral pH. Biomacromolecules 2014, 15, 699-706. [CrossRef] [PubMed]

160. Nowak, A.P.; Breedveld, V.; Pakstis, L.; Ozbas, B.; Pine, D.J.; Pochan, D.; Deming, T.J. Rapidly recovering hydrogel scaffolds from self-assembling diblock copolypeptide amphiphiles. Nature 2002, 417, 424-428. [CrossRef] [PubMed]

161. Ghoorchian, A.; Simon, J.R.; Bharti, B.; Han, W.; Zhao, X.; Chilkoti, A.; López, G.P. Bioinspired Reversibly Cross-linked Hydrogels Comprising Polypeptide Micelles Exhibit Enhanced Mechanical Properties. Adv. Funct. Mater. 2015, 25, 3122-3130. [CrossRef]

162. Sano, K.-I.; Kawamura, R.; Tominaga, T.; Oda, N.; Ijiro, K.; Osada, Y. Self-Repairing Filamentous Actin Hydrogel with Hierarchical Structure. Biomacromolecules 2011, 12, 4173-4177. [CrossRef] [PubMed]

163. Sathaye, S.; Mbi, A.; Sonmez, C.; Chen, Y.; Blair, D.L.; Schneider, J.P.; Pochan, D.J. Rheology of peptide- and protein-based physical hydrogels: Are everyday measurements just scratching the surface? WIREs Nanomed. Nanobiotechnol. 2015, 7, 34-68. [CrossRef] [PubMed]

164. Jacob, R.S.; Ghosh, D.; Singh, P.K.; Basu, S.K.; Jha, N.N.; Das, S.; Sukul, P.K.; Patil, S.; Sathaye, S.; Kumar, A.; et al. Self healing hydrogels composed of amyloid nano fibrils for cell culture and stem cell differentiation. Biomaterials 2015, 54, 97-105. [CrossRef] [PubMed]

165. Cai, L.; Dewi, R.E.; Heilshorn, S.C. Injectable Hydrogels with In Situ Double Network Formation Enhance Retention of Transplanted Stem Cells. Adv. Funct. Mater. 2015, 25, 1344-1351. [CrossRef] [PubMed]

166. Murphy, S.V.; Atala, A. 3D bioprinting of tissues and organs. Nat. Biotechnol. 2014, 32, 773-785. [CrossRef] [PubMed]

167. Kirchmajer, D.M.; Gorkin, R., III; in het Panhuis, M. An overview of the suitability of hydrogel-forming polymers for extrusion-based 3D-printing. J. Mater. Chem. B 2015, 3, 4105-4117. [CrossRef]

168. Wu, G.-H.; Hsu, S.-H. Review: Polymeric-Based 3D Printing for Tissue Engineering. J. Med. Biol. Eng. 2015, 35, 285-292. [CrossRef] [PubMed] 
169. Jungst, T.; Smolan, W.; Schacht, K.; Scheibel, T.; Groll, J. Strategies and Molecular Design Criteria for 3D Printable Hydrogels. Chem. Rev. 2015. [CrossRef] [PubMed]

170. Highley, C.B.; Rodell, C.B.; Burdick, J.A. Direct 3D Printing of Shear-Thinning Hydrogels into Self-Healing Hydrogels. Adv. Mater. 2015, 27, 5075-5079. [CrossRef] [PubMed]

171. Rodell, C.B.; Mealy, J.E.; Burdick, J.A. Supramolecular Guest-Host Interactions for the Preparation of Biomedical Materials. Bioconjug. Chem. 2015, 26, 2279-2289. [CrossRef] [PubMed]

172. Ozbolat, I.T. Bioprinting scale-up tissue and organ constructs for transplantation. Trends Biotechnol. 2015, 33, 395-400. [CrossRef] [PubMed]

173. Yu, L.; Ding, J. Injectable hydrogels as unique biomedical materials. Chem. Soc. Rev. 2008, 37, $1473-1481$. [CrossRef] [PubMed]

174. Bae, K.H.; Wang, L.-S.; Kurisawa, M. Injectable biodegradable hydrogels: Progress and challenges. J. Mater. Chem. B 2013, 1,5371-5388. [CrossRef]

175. Pape, A.C.H.; Bakker, M.H.; Tseng, C.C.S.; Bastings, M.M.C.; Koudstaal, S.; Agostoni, P.; Chamuleau, A.A.J.; Dankers, P.Y.W. An Injectable and Drug-loaded Supramolecular Hydrogel for Local Catheter Injection into the Pig Heart. J. Vis. Exp. 2015, 100, 52450. [CrossRef] [PubMed]

176. Gaffey, A.C.; Chen, M.H.; Venkataraman, C.M.; Trubelja, A.; Rodell, C.B.; Dinh, P.V.; Hung, G.H.; MacArthur, J.W.; Soopan, R.V.; Burdick, J.A.; et al. Injectable shear-thinning hydrogels used to deliver endothelial progenitor cells, enhance cell engraftment, and improve ischemic myocardium. J. Thorac. Cardiovasc. Surg. 2015, 150, 1268-1277. [CrossRef] [PubMed]

177. Yu, B.; Wang, C.; Ju, Y.M.; West, L.; Harmon, J.; Moussy, Y.; Moussy, F. Use of hydrogel coating to improve the performance of implanted glucose sensors. Biosens. Bioelectron. 2008, 23, 1278-1284. [CrossRef] [PubMed]

178. Goodman, S.B.; Yao, Z.; Keeney, M.; Yang, F. The Future of Biologic Coatings for Orthopaedic Implants. Biomaterials 2013, 34, 3174-3183. [CrossRef] [PubMed]

179. Agarwal, R.; García, A.J. Biomaterial strategies for engineering implants for enhanced osseointegration and bone repair. Adv. Drug Deliv. Rev. 2015, 94, 53-62. [CrossRef]

180. Zhang, S.; Bellinger, A.M.; Glettig, D.L.; Barman, R.; Lee, Y.-A.L.; Zhu, J.; Cleveland, C.; Montgomery, V.A.; $\mathrm{Gu}, \mathrm{L}$; Nash, L.D.; et al. A pH-responsive supramolecular polymer gel as an enteric elastomer for use in gastric devices. Nat. Mater. 2015, 14, 1065-1071. [CrossRef] [PubMed]

181. Luo, F.; Sun, T.L.; Nakajima, T.; Kurokawa, T.; Ihsan, A.B.; Li, X.; Guo, H.; Gong, J.P. Free Reprocessability of Tough and Self-Healing Hydrogels Based on Polyion Complex. ACS Macro Lett. 2015, 4, 961-964. [CrossRef]

182. Cameron, A.R.; Frith, J.E.; Gomez, G.A.; Yap, A.S.; Cooper-White, J.J. The effect of time-dependent deformation of viscoelastic hydrogels on myogenic induction and Rac1 activity in mesenchymal stem cells. Biomaterials 2014, 35, 1857-1868. [CrossRef] [PubMed]

(C) 2016 by the authors; licensee MDPI, Basel, Switzerland. This article is an open access article distributed under the terms and conditions of the Creative Commons Attribution (CC-BY) license (http://creativecommons.org/licenses/by/4.0/). 